Article

\title{
An Efficient Model for NPD Performance Evaluation Using DEMATEL and Fuzzy ANP-Applied to the TFT-LCD Touch Panel Industry in Taiwan
}

\section{Wen-Chin Chen ${ }^{1, *}$, Hui-Pin Chang ${ }^{2}$, Kuan-Ming Lin ${ }^{3}$ and Neng-Hao Kan ${ }^{1}$}

1 Department of Industrial Management, Chung-Hua University, No. 707, Sec. 2, WuFu Rd., Hsinchu 30012, Taiwan; E-Mail: maimaihsin@gmail.com

2 College of Management, Chung-Hua University, No. 707, Sec. 2, WuFu Rd., Hsinchu 30012, Taiwan; E-Mail: dejyhpcarole@gmail.com

3 Department of Foreign Languages \& Literatures, Chung-Hua University, No. 707, Sec. 2, WuFu Rd., Hsinchu 30012, Taiwan; E-Mail: bob@chu.edu.tw

* Author to whom correspondence should be addressed; E-Mail: wenchin@chu.edu.tw; Tel.: +886-03-518-6585; Fax: +886-03-518-6575.

Academic Editor: Enrico Pontelli

Received: 9 June 2015 / Accepted: 12 October 2015 / Published: 22 October 2015

\begin{abstract}
As the competitive market nowadays shortens the life cycle of products, new products should be designed to meet the customer's demand under a dynamic marketing environment so as to efficiently enhance the product strength of new products with maximization of profit. Hence, the key solution for enterprises to succeed will be the precise evaluation of new product development (NPD) performance, particularly for those who manage to survive in the intensely competitive market in Taiwan. This study is to identify the thin film transistor-liquid crystal display (TFT-LCD) touch panel industry and then establish an integrated model of NPD performance evaluation for enterprises. Firstly, literature review and interviews with experts are conducted to select the four aspects and 15 criteria as the main factors affecting NDP performance evaluation. Secondly, Decision Making Trial and Evaluation Laboratory (DEMATEL) is employed to identify the interrelationships among those factors. Finally, a Fuzzy theory is applied to resolve the linguistic hedges and an Analytic Network Process (ANP) is adopted to obtain the weights of all factors. A case study is performed to validate the proposed model in a Taiwanese TFT-LCD company. It not only provides the decision maker with a guidance system but also increases the competitive advantages for the TFT-LCD industry to design new products in the future.
\end{abstract}


Keywords: NPD; TFT-LCD; DEMATEL; fuzzy theory; ANP

\section{Introduction}

The 21 st century is the era of mature technologies and the phase of a rapid transformation, leading to dramatic changes in people's lifestyles and consumption behaviors. Those characteristics are usually reflected in the concept of production design. People appeal for products that are fast and intelligent, thus product development is often carried out based on the concept of fast operation and product independence system. In particular, the touch panel is the easiest approach for fast operation and can be used as a basic element of product operational interface. Due to the mature technology of panels in recent years, new product development (NPD) has emphasized the touch panel system as the operational interface for smart phones, tablet PCs, laptop computers, touch TVs, and other touch-type devices. To meet the market demand, the productivity of touch panels have substantially increased. Currently, most of the world's LCD monitors are produced in Japan, Taiwan, South Korea, and China. Under the intense competition among these countries, it is extremely important for enterprises to maintain their advantages in market competitiveness and create new technologies in order to secure their market share.

As in the example of Japan, its intention is to control the critical technology in thin film transistor-liquid crystal display (TFT-LCD) industries and take aggressive measures in developing the next-generation monitor technology through industrial-academic collaboration of R\&D technology. Thus, Japan strives to lead industry development from the top of industry upstream in addition to owning core technology and industrial components. The strength of such approach lies in the R\&D product technology and the weakness is the lack of planning in production, therefore Japan commissions manufacturing to other countries. South Korea focuses on the competition of exporting brand products plus the government assistance in R\&D that contributes to industry technology upgrade, and thereby competition with other countries. Its strength lies in the strong enterprise power as well as the capacity of vertical integration. The weakness of South Korea is its own regulations of product development, which could affect the overall industry development of TFT-LCD once an incorrect decision is made. China is currently aggressively expanding its productivity and establishing its industry chain. From the viewpoint of Taiwan, internal weakness caused by the characteristics of TFT-LCD industry plus the external threats from the competitive strengths of other countries have driven Taiwan's TFT-LCD industry to develop new products and new technologies in R\&D industry by lowering the production cost. Under the dual pressure, to maintain the leadership of TFT-LCD market, Taiwan is facing a dilemma, increasing market competitiveness and keeping the leadership in the market share of TFT-LCD industry.

Under the trend of globalization, the technology of TFT-LCD requires constant improvement and development of new products for meeting the customer's demand in order to maintain the corporate competitive advantages. The success of developing a new product can bring impressive revenue for the enterprise. Nonetheless, the process of developing a new product from the stages of design, experiments, and mass production to sales is considerably complicated. Enterprises often lack the reference of evaluation factors for developing a new product, so they often apply experience and decision-making models instead; however, the outcome usually falls below expectation. Moreover, NPD usually requires 
the investment of funding in R\&D, new technologies and equipment purchase. The performance of NPD is very important to the product competitiveness and the improved life cycle of products can greatly fulfills the customer's demand. Systematic development of new products and the performance evaluation of NPD are successful strategies that effectively sell new products and become the main focus of the enterprises.

\section{Literature Review}

Since NPD can greatly affect the future development of TFT-LCD, thus, enterprises must take considerations for the influential factors of NPD in order to make a correct decision. This study uses the TFT-LCD industry in Taiwan as the research background and establishes a new performance evaluation model in NPD through Decision Making Trial and Evaluation Laboratory (DEMATEL) and Fuzzy Analytic Network Process (FANP). The TFT-LCD industry can apply this performance evaluation model to the design and development of new products.

\subsection{TFT-LCD Industry in Taiwan}

Thin film transistor-liquid crystal display (TFT-LCD) is an active matrix monitor mainly formed by two glass substrates with one layer of liquid crystal in the middle; the top-layer glass substrate is a combination of color filter, the lower-layer glass is covered with transistors. When current flows through the transistors and results in change in electric fields, it will result in liquid crystal molecule shift that will change the deflection polarity of lights. The polarizer is used to determine the lighting of resolution, and the top-layer glass the color filters are adhered to comprise three colors, blue, green and red, using the RGB to build the image screen.

The TFT-LCD industry possesses huge capital and top technologies, which require the investment of tens of billions of NT Dollars for purchases from new plant layout and R\&D technology to mass production. Under the characteristics of capital intense industry, the amount of massive funding invested in purchasing new equipment must result in relatively higher productivity. Thus, barriers to the TFT-LCD industry and reasons to withdraw from the TFT-LCD market appear. In addition, the technology of TFT-LCD itself is complex and abstruse: from the characteristics of upstream materials and components through the midstream flat panel process and modularization technology, and finally to the electronic system products in the downstream application market. The technology continuously develops and innovates while enterprises must invest in massive funding in the R\&D and purchase new equipment in attempt to increase productivity in a short period of time. Consequently, the price of TFT-LCD is significantly affected by the market demand and supply. In a market of price-based competition, enterprises take considerations of cost allocation and establish factories in developing countries, while the headquarters control the marketing, new technology R\&D, and NPD, resulting in division of labor internationally.

Taiwan is internationally renowned for its technology development. The development of the panel industry in Taiwan has been initiated since 1976, answering the market demand for panel and following the progress of technology. At that time, the United States of America offered technology and capital, while Taiwan offered factories and labor to start production from twisted nematic (TN) Liquid Crystal monitors. By 1990, the progress in Taiwan's technology and increase in production cost drove China to 
enter the monitor industry. Taiwan developed super-twisted nematic (STN) monitors to enhance its market competitiveness, and under the support of Ministry of Economic Affairs and the Industrial Technology Research Institute (ITRI), the enterprise developed Thin Film Transistor Liquid Crystal Display (TFT-LCD) and peripheral IC components. Meanwhile, the formation of industrial parks resulted in industry clustering effect, and such effect contributed to a quick path to mass production.

The key to the success of the development of Taiwanese TFT-LCD industry lies in the capability of the integration of industry planning, cost advantage, flexibility of production schedule, and R\&D. The TFT-LCD industries in Taiwan mainly gather in three science parks, Hsinchu Science Park, Taichung Science Park and Tainan Science Park. The integration of North, Central and South Science Parks in western Taiwan turns Taiwan into a photovoltaic island; meanwhile, the industry clustering effect promotes the development of relevant material and component industries. Moreover, the ODM characteristics of Taiwan's IT industries have improved the integrity of the upstream, midstream and downstream industrial structure of TFT-LCD, which aggressively develops to a globally significant industrial cluster. Due to the maturity of TFT-LCD panel product technology, market competition, the declining growth and the overall economic downturn, the price of products has fallen. To control the cost, the enterprises have to adjust the operating ratio while making adjustment in their product lines by expanding the production of new specifications and products with more advanced processing. Besides, the maturity of the TFT-LCD technology has led the product price close to the cost, while the market saturation slows down the growth rate of the productivity. Thus, only the development of new products can expand the new market. For these reasons, the study develops an NPD performance evaluation model in terms of the proprietary characteristics of TFT-LCD industries in Taiwan.

\subsection{NPD}

In the environment of quick changing, the life cycle of products tends to shorten despite the stable market share of the product; therefore, only new product development (NPD) can help the enterprises to thrive with more developmental opportunities. NPD is highly associated with engineering technology, manufacturing, financial, and management departments. Some scholars mentioned that improved technology is one of the key success factors to the successful development of new products [1-4]. Many studies reveal that the management should understand the market and conduct benchmarking for competitors in the process of developing new products, while maintaining close attention to the development trend of the application market [5-11]. Cooper suggested that the variables to the strategies of new product development can be divided into four characteristics as described below: (1) the enterprise's new product orientation, including creative new products, developing products that better meet the customer's demand than the competitors, product centralization and differentiation; (2) market characteristics appealed by new products, including the new market, customers, competitors, or new sales channels; (3) the enterprise's technology orientation and commitment, including the percentage of $R \& D$ expense to sales revenue, corporate $R \& D$ orientation and so forth; and (4) technical properties cited by the new product, including advanced/complex technology, close cooperation between the new product and company $R \& D$, technology maturity and centralization [12,13]. Firth and Narayanan applied three aspects to define the strategies of new products: (1) newness of embodied technology; (2) newness of market applications; and (3) innovativeness in the market [14]. Marion et al. suggested 
that the failure in NDP can result in potential risks for enterprises, and the management of NDP for new enterprises. The core to NDP is controlled by the management of enterprise, which needs to be applied with creativity, innovation, execution, technology, teamwork, and integration capacity. Every step taken in product development comes with extreme influence, including customer response, coercion from competitors, technical risks, interdepartmental cooperation, and resource fork [15]. Chen et al. suggested that successful NPD is not only an important part of competitive advantage, but also the way to sustain the system of management and development; and particularly, it should be more noticed during economic downturns. The study conducted NPD performance evaluation of enterprises using the five aspects, including product characteristics of development team, market trends, new product features, information resources and technology, and strategic planning [16]. Ulrich and Eppinger suggested that NPD includes two criteria of high relevance: technological feasibility and market profitability, which are also used as the primary criteria for effectiveness and high efficiency in new product performance evaluation. Enterprises can adopt different methods to conduct performance evaluation according to the characteristics. Strategies and design experts' definition of NPD are also summarized to understand the importance of NPD for enterprises in-depth, which will facilitate the continuous development of enterprises, as well as becoming the key core objectives for enterprises to improve their competitive advantages [17].

\subsection{DEMATEL}

Decision making trial and evaluation laboratory (DEMATEL) was proposed by Gabus and Fontela [18] for the application of solving complex problems. DEMATEL is to yield casual dimensions and intensity of impact by using matrix computation through direct comparison of the interrelation between criterions. Such structure matrix and casualty matrix are used to express the relationship between properties in order to find the core issues of evaluation system, and such methods benefit the decision-maker in terms of execution. DEMATEL is frequently applied to multiple criteria decision making (MCDM) to understand the core problems and construct evaluation performance model through the mutual impact between factors and the cause-and-effect diagram drawn based on the significance. Chen and Chen discussed the innovative performance of Taiwan's advanced education institutes in academic research, and used DEMATEL, FANP and TOPSIS to find out the relative weight of each measurement criteria, thereby to evaluate how to form the ideal solution and technology that will support the system through development innovation [19]. Büyüközkan and Çifçi expressed that enterprise respond to increased public awareness following the environmental impact, while environmental (green) criteria and strategies become more important. The environmental performance of enterprises is not only related to the internal efforts of enterprises but also subject to the impact from the environmental performance and image of suppliers. Nonetheless, the choice of suppliers is a complex and multiple criteria decision-making problem. Therefore green supply chain management and the capacity of green supply china management should be employed as the base to combine MCDM with DEMATEL in order to find the core factor to build the green supplier evaluation model for automobile companies using ANP and TOPSIS [20]. Yet and Huang studied the key factors in determining wind farm location. DEMATEL and ANP were employed to search for the correlation between the dimensions and the relative weights of the criteria [21]. Hornga et al. analyzed the interior design and creativity of restaurants and the six 
factors under the evaluation model, using DEMATEL to determine the interrelation between factors according to the influence and importance, seeking core factor that can be used as the main consideration factor of restaurant interior design [22]. Abdollahi et al. applied DEA, DEMATEL and ANP to select an appropriate supplier portfolio. A case study was performed to validate the model and to demonstrate its applicability and feasibility [23]. This study applies DEMATEL to find the interrelation between performance indices to establish the criteria network structure in the FANP model.

\subsection{FANP}

Analytic Hierarchy Process (AHP) was proposed by Saaty [24] as a method used in decision-making, with the purpose to solve uncertainties and multiple criteria decision making as well as the substitution of priority solutions. AHP is an analytical method that combines qualitative analysis and quantitative analysis with systematics and hierarchy. Ayağ systemized complex problems through a hierarchical structure to set up criteria to differentiate relevant items while the criteria are mutually independent without affecting each other, to conduct criteria evaluation through paired comparison, to make large complex problems easier for decision making [25]. AHP was applied to a broad range of problems, including corporate planning, project option, product planning, resource allocation, and priority choice, which successfully apply to solve problems in various fields [26-28]. Nonetheless, in practice, decision-making could have a dependent relationship between criteria. Saaty extended AHP by proposing analytic network process (ANP) to solve the interdependence relationship between criteria and take into consideration internal interdependence and feedback issues. When evaluating decision-making criteria, not only do criteria from the same hierarchy affect each other, but there is also an interdependence relationship between criteria of different hierarchy [29]. Therefore, aspects and criteria are not just linear hierarchical structure but a presentation of network model. ANP can clearly identify the independence relationship between aspects and criteria [30]. However, decision makers can adjust the order of priority for substituting solutions according to the extent of relation, which can break the limitation of traditional AHP criteria independence while more precisely understand the internal problems between the aspects and the elements [31,32].

Different environments, change of time and self-governing awareness will result in different decision-making outcome in the process accompanied by uncertainties. Zadeh proposed fuzzy theory with the intention to solve linguistic fuzzification and thereby strengthen human thinking and uncertain words appeared in judgment through quantitative method [33]. The fuzzy theory is usually combined with other theories to derive new theories, such as Fuzzy Delphi Method (FDM) [34-37], Fuzzy Quality Function Deployment (FQFD) [38-40], Fuzzy Analytic Hierarchy Process (FAHP) [41-44], Fuzzy Analytic Network Process (FANP) and so forth.

In the past, many scholars have applied the fuzzy theory to solve linguistic fuzzification when studying decision-making, using the Fuzzy Analytic Network Process (FANP). Promentilla et al. applied FANP to analyze the evaluation on improvement measures for polluted sites, using $\alpha$ cut to substitute certain matrix with interval calculation and optimistic index, followed by calculating priority weight through eigenvalues [45]. Selvkli et al. used FANP model to establish a management evaluation model applied to Turkish aviation industries and provided strategic management model and suggestions [46]. Chen and Chang studied the example for solar module to apply FANP in the discussion 
of evaluation improvement for new product development solutions [47]. Rezaeiniya et al. proposed a hybrid MCDM method based on FANP for investors to select greenhouse locations in Iran [48]. Chang et al. employed FANP method to assess ERP implementation risks for intra-organizational cultures and across-industries [49].

This study conducts research on the performance evaluation of Taiwan's TFT-LCD touch panel companies by constructing a performance evaluation model for NPD. This study identifies the issues and demands faced by TFT-LCD in NPD, through a relevant literature collection and interviews with the experts to preliminarily draft the aspects, and criteria to screen factors through interviews with experts of the performance index for the evaluation of NPD. Decision Making Trial and Evaluation Laboratory (DEMATEL) is employed to find out the degree and direction of impact from each performance index, and to draw the network structure of each index. Fuzzy Analytic Network Process (FANP) is applied to analyze the aspects and criteria weights, and weights are used to find out the critical impact factors of the NPD performance. The results of undergoing factor analysis on the performance evaluation of Taiwan's TFT-LCD touch panel enterprises will be provided to the industry for future reference in project execution.

\section{Proposed Model for the NDP Performance Evaluation of TFT-LCD Touch Panel Enterprises}

This study analyzes the NPD performance evaluation relating to TFT-LCD touch panels and applies relevant literature collection to preliminarily draft the aspects and criteria. In the first phase, interviews with experts are conducted to carry out screening, and the aspects and criteria screened out can be used as the performance indices for NPD. In the second phase, DEMATEL is applied to find the extent impact and direction between performance indices in order to determine the network structure of each evaluation index. In the third phase, FANP is applied to search for the aspect and criteria weights. Weights are used as reference to improve NPD performance. The results of undergoing factor analysis on the performance evaluation of Taiwanese TFT-LCD touch panel enterprises will be provided to enterprises for reference in project execution.

\subsection{Identifying the Evaluation Criteria of NPD}

This study discusses influence factors to TFT-LCD new product development through literature review, followed by acquiring expert views and opinions through interview with experts to carry out screening and to validate the validity of aspects and criteria in performance measurement.

\subsection{Developing the Network Structure}

Decision making trial and evaluation laboratory (DEMATEL) was proposed by the Battelle Memorial Institute [18] for the application of solving complex problems. The DEMATEL technique establishes the interrelations between aspects/criteria to build system relations. This study establishes and screens the evaluation criteria through the first step, uses the mutual impact of measurement criteria in a five-point Likert scale, and converts them into average influence relationship matric through equalization for DEMATEL. The computation of DEMATEL can calculate the criteria relevance and 
level of impact and establish structural relationship of criteria through the level of impact. The definitions are described in the following sections.

\subsubsection{Establish Direct-Relation Matrix}

Developing the direct-relation matrix is to sum up all vectors and take the sum of maximum vectors as the benchmark of form, and the initial direct-relation matrix $D$ is shown in Equation (1). The normalized direct-relation matrix $(X)$ can be obtained by calculating Equations (2) and (3).

$$
\begin{gathered}
D=\left[\begin{array}{cccc}
0 & D_{12} & \cdots & D_{1 j} \\
D_{21} & 0 & \cdots & D_{2 j} \\
\vdots & \vdots & \ddots & \vdots \\
D_{i 1} & D_{i j} & \cdots & 0
\end{array}\right] \\
\lambda=\frac{1}{\max _{1 \leq i \leq n}\left(\sum_{j=1}^{n} D_{i j}\right)} \\
X=\lambda \times D
\end{gathered}
$$

\subsubsection{Total-Relation Matrix}

Substitute the direct-relation matrix $X$ into Equation (4) to calculate the total-relation matrix $(T)$, while the direct-relation matrix can also been addressed as the total-relation matrix. Particularly, the unit matrix $I$ is defined in Equation (5), and all criteria direct-relation matrices are combined to become the total-relation matrix.

$$
\begin{gathered}
T=\lim _{\mathrm{k} \rightarrow \infty}\left(X^{1}+X^{2}+\cdots+X^{k}\right)=X(I-X)^{-1} \\
I=\left[\begin{array}{ccccc}
1 & 0 & 0 & \cdots & 0 \\
0 & 1 & 0 & \cdots & \vdots \\
0 & 0 & 1 & \cdots & 0 \\
\vdots & \vdots & \vdots & \ddots & \vdots \\
0 & 0 & 0 & \cdots & 1
\end{array}\right]
\end{gathered}
$$

\subsubsection{Calculate Relevance and Level of Impact}

Calculate the sum of $D_{i}$ on each column and the sum of $R_{j}$ on each row, respectively, as shown in Equations (6) and (7), where $D_{i}$ denotes the level of impact directly and affects other criteria; $R_{j}$ denotes the level; and criterion $\mathrm{j}$ is directly affected by other criteria. $D_{i}+R_{j}$ denotes relevance, signifying the intensity of relationship between criterion. $D_{i}-R_{j}$ denotes level of impact, also known as the intensity which criteria affect or are affected.

$$
\begin{aligned}
D_{i} & =\sum_{j=1}^{n} x_{i j}, i=1,2,3, \ldots, n \\
R_{j} & =\sum_{i=1}^{n} x_{i j}, j=1,2,3, \ldots, n
\end{aligned}
$$




\subsubsection{Build Causal Diagram for Evaluation System}

By using 2D coordinates as the base of casual diagram and taking $D_{i}+R_{j}$ as $X$-axis and $D_{i}-R_{j}$ as $Y$-axis, the relevance and level of impact of each criterion is marked on the coordinates. The casualty between criteria is drawn according to the threshold in addition to conducting analysis. In particular, if $D_{i}-R_{j}$ is positive value, it suggests that $i$ affects criterion $j$; on the contrary, if $D_{i}-R_{j}$ is a negative value, it suggests that $j$ affects criterion $i$.

\subsubsection{Complete the DEMATEL Hierarchical Structure}

When the impact value and relevance value of each aspect and criterion are obtained. The NPD performance evaluation model is drawn based on the relation of casual diagram.

\subsection{Obtaining the Priority Order of the Strategies}

This phase aims to derive the weights of aspects and criteria in new product design through the application of FANP. This study employs the nine-point scale of relevance proposed by Saaty [50] to design the FANP questionnaire. The experts serve as decision makers in TFT-LCD industry for the survey, while FANP is processed as follows:

(1) Form the network structure with well-defined goal, the aspects and criteria, where the relationship of the external criteria and internal relationship of criteria are determined in the final phase.

(2) Form pair-wise comparison matrices through the scale of one to nine points received from all experts' responses to the questionnaires.

(3) Obtain the weights and analyze consistency. The priority of the criteria can be compared by the calculation of eigenvectors and eigenvalues.

$$
\begin{gathered}
w_{i}=\frac{1}{n} \sum_{j-1}^{n} \frac{a_{i j}}{\sum_{i}^{n} a_{i j}}, \forall i=1,2,3, \ldots n \\
A \times W=\lambda_{\max } \times W
\end{gathered}
$$

where $w_{i}$ is the eigenvector of matrix $A$ gained from Formula (9), and $\lambda_{\max }$ is the largest eigenvalue in the matrix $A$. The pairwise matrixes are then examined with consistency index (C.I.) and consistency ratio (C.R.) to see if each pairwise comparison matrix reaches the consistency. This phase aims to derive the weights of the aspects and criteria in new product design by applying FANP. This study employs the 9-point scale of relevance proposed by Saaty [51] to design the FANP questionnaire. The pair wise matrixes are then examined with consistency index (C.I.) and consistency ratio (C.R.) to determine if each pair wise comparison matrix reaches consistency. If the value of C.R. is greater than the threshold, the consistency test fails and the original entries in the matrix will need to be reviewed and revised by the decision maker.

$$
\begin{gathered}
\text { C. } I .=\frac{\lambda_{\mathrm{MAX}}-n}{n-1} \\
\text { C. R. }=\frac{\text { C.I. }}{\text { R.I. }}
\end{gathered}
$$


(4) Create fuzzy positive matrixes. The entries in the pair wise comparison matrixes are transformed into positive triangular fuzzy numbers, known as linguistic variables. As suggested by Buckley [52], the fuzzy positive reciprocal matrix can be defined as Equations (12) and (13).

$$
\begin{gathered}
\tilde{R}^{k}=\left[\tilde{r}_{i j}\right]^{k} \\
\tilde{r}_{i j}=1, \forall i=j ; \\
\tilde{r}_{i j}=\frac{1}{\tilde{r}_{j i}}, \forall i, j=1,2, \ldots . ., n
\end{gathered}
$$

where $\tilde{R}^{k}$ is a positive reciprocal matrix of decision maker $k$; and $\tilde{r}_{i j}$ is the relative importance between decision factors $i$ and $j$.

Compute the fuzzy weights of decision factors.

(5) Combine the determinants of all members of the decision-making team. Geometric average means is used to integrate the fuzzy weight matrixes of experts.

(6) Process the defuzzification to obtain the final sequence order of decision factors. Based on the equation proposed by Chen [53], the closeness coefficient is defined as follows: the purpose is to obtain the center of triangular object, while the center value in fuzzy theory denotes the entire fuzzification collection, converting the values $\mathrm{a}_{i}, \mathrm{~b}_{i}$, and $\mathrm{c}_{i}$ from the fuzzification collection $B_{i j}=\left(a_{i}, b_{i}, c_{i}\right)$ into $B_{i j}$ through Equation (14).

$$
B_{i j}=\frac{\left(c_{i j}-a_{i j}\right)+\left(b_{i j}-a_{i j}\right)}{3}+a_{i j}
$$

(7) Create super-matrix. Each sub-matrix with priority vectors will be combined into an initial super-matrix. As it may not fit the column stochastic rule, each column matrix will be normalized to form a weighted super-matrix. Finally, the weighted super-matrix is multiplied until reaching Equation (15) with convergence.

$$
\lim _{k \rightarrow \infty} S^{2 k+1}=\lim _{k \rightarrow \infty} S^{2 k}
$$

\section{Case Study}

This study analyzes the NPD performance for TFT-LCD touch panel companies to find out the primary factors affecting TFT-LCD touch panel, the NPD performance as the performance index, and the reference for decision makers in the new product development. This study can be divided into three phases, where literature collection and interviews with experts are conducted in the preliminary phase to build the aspects and criteria. Moreover, the Decision Making Trial and Evaluation Laboratory (DEMATEL) is employed to calculate the mutual impact between aspects and criteria, and thus validates the structural relationship in aspects and criteria. The third phase is to build the new product development performance evaluation model for the TFT-LCD touch panel. Fuzzy Analytic Network Process (FANP) is applied to acquire the hierarchical weights through paired comparison and multiple comparisons, which are weighted on the basis of the super matrix computation, and the weight sequence is sorted to find out the key index between the aspects and criteria affecting NPD of the TFT-LCD touch panel 
industry. Decision makers can use such research results as reference for the NPD of the TFT-LCD touch panel industry in Taiwan.

\subsection{Identifying the Evaluation Aspects and Criteria of NPD}

To precisely find out the key success factors affect new product development (NPD), the literature on past studies is compiled and undergoes screening and validation by experts. The experts refer to the R\&D, engineering and marketing department supervisors of TFT-LCD industry, who have many experiences in the TFT-LCD touch pane industry. Thus, the experts can explicitly point out the key success factors to new product development. The number of the committee members is six experts. Literature compilation and experts' discussion suggest that four aspects and 15 criteria constitute the key success factors, as shown in Table 1.

Table 1. Critical success factors for NPD.

\begin{tabular}{cc}
\hline Aspects & Sub Criteria \\
\hline \multirow{2}{*}{ Market Assessments (MA) } & S11 Product Life Cycle \\
& S12 Regulatory Certification \\
S13 Validate Goal Market \\
S14 Sales Forecast \\
\hline Customer Demands (CD) & S21 Product Quality Attributes \\
& S22 Product Pricing \\
& S23 After-Sales Service \\
Production Requirements (PR) & S24 Product Quality Rate \\
\hline & S31 Manufacturing Capacity \\
& S33 New Product Attributes \\
\hline Quality Criteria (QC) & S41 High and Low Temperature Test \\
& S42 High Temperature and High Humidity Test \\
& S43 High Impact Test \\
& S44 Writing Durability \\
\hline
\end{tabular}

\subsection{DEMATEL}

This phase shows the understanding of the four aspects and 15 criteria through DEMATEL to build a network diagram of key success factors to new product development. This study applies the mutual relation of each factor through six experts. The following describes the steps of DEMATEL execution.

\subsubsection{Direct-Relation Matrix}

After consolidating expert opinions, the direct relation matrix $(D)$ is yielded, as shown in Table 2. The vectors of the row and column in direct relation matrix are further summed up to find the maximum vector sum of the column and row (7.591). Substitute $\lambda$ value of 0.132 into Equation (3) to calculate and to get the normalized direct-relation matrix $(X)$, as shown in Table 3. 
Table 2. Direct-Relation Matrix $(D)$ for Aspects.

\begin{tabular}{ccccc}
\hline Aspects & $\begin{array}{c}\text { Market } \\
\text { Assessments }\end{array}$ & $\begin{array}{c}\text { Customer } \\
\text { Demands }\end{array}$ & $\begin{array}{c}\text { Product } \\
\text { Requirements }\end{array}$ & $\begin{array}{c}\text { Quality } \\
\text { Criteria }\end{array}$ \\
\hline Market Assessments & 0 & 2.426 & 2.747 & 2.193 \\
Customer Demands & 2.011 & 0 & 3.182 & 2.398 \\
Production Requirements & 1.347 & 1.557 & 0 & 1.483 \\
Quality Criteria & 1.540 & 1.614 & 2.657 & 0 \\
\hline
\end{tabular}

Table 3. Normalized Direct-Relation Matrix (X) for Aspects.

\begin{tabular}{ccccc}
\hline Aspects & $\begin{array}{c}\text { Market } \\
\text { Assessments }\end{array}$ & $\begin{array}{c}\text { Customer } \\
\text { Demands }\end{array}$ & $\begin{array}{c}\text { Product } \\
\text { Requirements }\end{array}$ & $\begin{array}{c}\text { Quality } \\
\text { Criteria }\end{array}$ \\
\hline Market Assessments & 0.000 & 0.330 & 0.373 & 0.298 \\
Customer Demands & 0.265 & 0.000 & 0.432 & 0.326 \\
Product Requirements & 0.177 & 0.212 & 0.000 & 0.202 \\
Quality Criteria & 0.203 & 0.219 & 0.361 & 0.000 \\
\hline
\end{tabular}

\subsubsection{Total-Relation Matrix}

After calculating the normalized relation matrix $(X)$ from the previous step, substitute matrix $(X)$ into Equation (4) to calculate the direct/indirect relation matrix (T), as shown in Table 4. The next step will calculate the association and impact between aspects: substitute the matrix values into Equations (6) and (7) to yield $D_{i}$ value and $R_{j}$ value, which in addition to a summary, are found in Table 5. In particular, $D_{i}+R_{j}$ represents the relevance between aspects, whereas $D_{i}-R_{j}$ denotes impact value.

Table 4. Total-Relation Matrix (T) for Aspects.

\begin{tabular}{ccccc}
\hline Aspects & $\begin{array}{c}\text { Market } \\
\text { Assessments }\end{array}$ & $\begin{array}{c}\text { Customer } \\
\text { Demands }\end{array}$ & $\begin{array}{c}\text { Product } \\
\text { Requirements }\end{array}$ & $\begin{array}{c}\text { Quality } \\
\text { Criteria }\end{array}$ \\
\hline Market Assessments & 0.948 & 1.324 & 1.795 & 1.375 \\
Customer Demands & 1.155 & 1.073 & 1.828 & 1.389 \\
Product Requirements & 0.777 & 0.884 & 1.006 & 0.925 \\
Quality Criteria & 0.929 & 1.042 & 1.489 & 0.917 \\
\hline
\end{tabular}

Table 5. Relevance and Impact between Aspects after Integration.

\begin{tabular}{cccccc}
\hline No. & Name of Aspects & $\boldsymbol{D}_{\boldsymbol{i}}$ & $\boldsymbol{R}_{\boldsymbol{j}}$ & $\boldsymbol{D}_{\boldsymbol{i}}+\boldsymbol{R}_{\boldsymbol{j}}$ & $\boldsymbol{D}_{\boldsymbol{i}}-\boldsymbol{R}_{\boldsymbol{j}}$ \\
\hline$O_{1}$ & Market Assessments & 1.276 & 0.0821 & 1.358 & 1.194 \\
$\mathrm{O}_{2}$ & Customer Demands & 1.153 & 0.2517 & 1.153 & 1.153 \\
$\mathrm{O}_{3}$ & Product Requirements & 0.000 & 1.8933 & 0.000 & 0.000 \\
$O_{4}$ & Quality Criteria & 0.416 & 0.6184 & 0.416 & 0.416 \\
\hline
\end{tabular}

\subsubsection{Causal Diagram}

The relevance value and impact value are set up in $2 \mathrm{D}$ coordinates, where relevance value $\left(D_{i}+R_{j}\right)$ is the $X$-axis, impact value $\left(D_{i}-R_{j}\right)$ is the $Y$-axis, and the aspect value is filled in. This study configures a threshold to highlight the casualty. In particular, the threshold value is 1.073 , which is the maximum 
value of diagonal elements within the total-relation matrix $(T)$. Through the configuration of threshold, a number smaller than the threshold shall be deleted, while a number greater than or equal to the threshold will be drawn on the coordinates to form the direct-relation casual diagram for aspects. The casual diagram is in Figure 1.

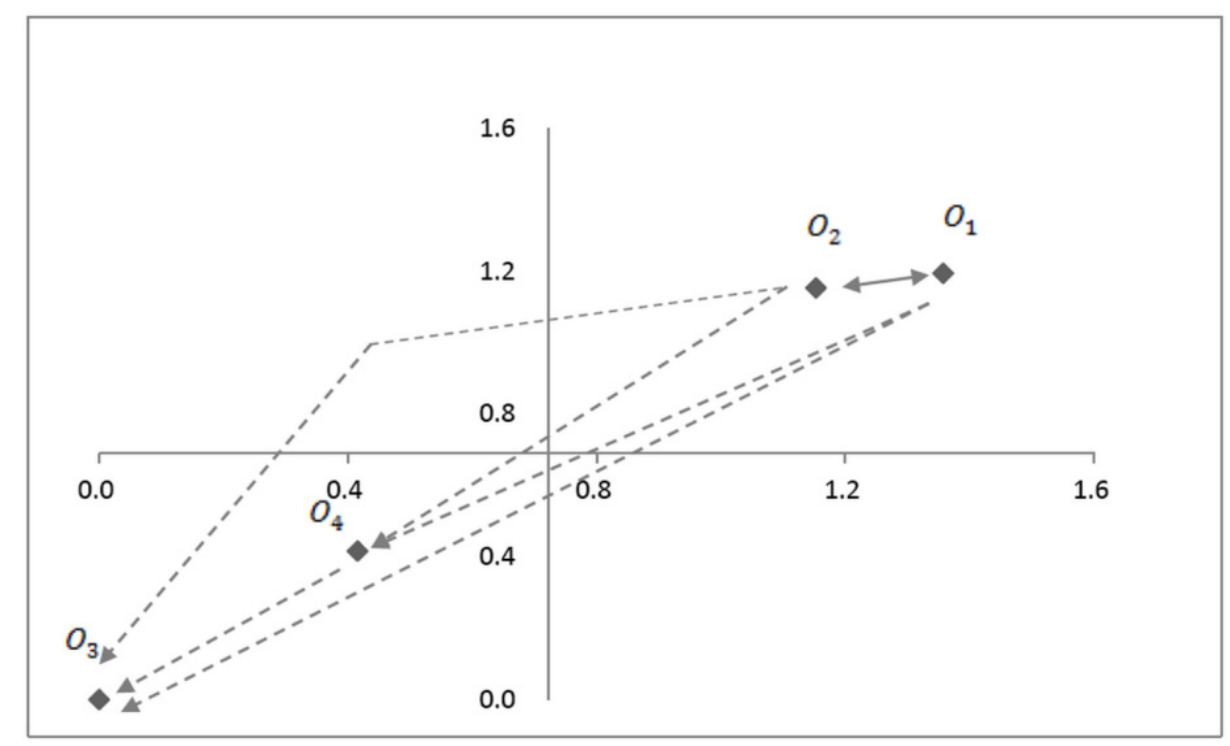

Figure 1. Casual Diagram for Aspects.

In the second stage, data are collected through the expert questionnaire and undergo DEMATEL analysis for criteria. The data are built with the direct-relation matrix $(D)$. The vectors of the row and column in the direct-relation matrix are, furthermore, summed to find the maximum vector sum of the column and row. Equation (3) is used to calculate and to get the normalized direct-relation matrix $(X)$. Equation (4) is employed to obtain the total-relation matrix $(T)$. The total-relation matrix $(T)$ and the relevance and impact between criteria are shown in Tables 6 and 7, respectively. In particular, the threshold value is equal to 0.225 , which is the maximum value of diagonal elements within the total-relation matrix $(T)$. Through the configuration of the threshold, numbers smaller than the threshold shall be deleted, while numbers greater than or equal to the threshold will be drawn on the coordinates to form the casual diagram. Figures A1-A15 (in the appendix) are the casual diagrams for each criteria. Finally, the impact value and relevance value of each aspect and criterion are inferred. Consequently the TFT-LCD NPD performance evaluation model is drawn based on the relation of casual diagram, which will be applied with FANP for calculation in next step, as shown in Figure 2. 
Table 6. Total-Relation Matrix (T) for Criteria.

\begin{tabular}{|c|c|c|c|c|c|c|c|c|c|c|c|c|c|c|c|}
\hline Criteria & S11 & S12 & S13 & S14 & S21 & $\mathbf{S 2 2}$ & $\mathbf{S 2 3}$ & S24 & S31 & S32 & S33 & S41 & $\mathrm{S} 42$ & S43 & S44 \\
\hline $\mathrm{S} 11$ & 0.221 & 0.249 & 0.273 & 0.273 & 0.357 & 0.306 & 0.274 & 0.298 & 0.302 & 0.240 & 0.302 & 0.259 & 0.264 & 0.254 & 0.258 \\
\hline $\mathrm{S} 12$ & 0.222 & 0.129 & 0.199 & 0.189 & 0.244 & 0.214 & 0.181 & 0.200 & 0.201 & 0.224 & 0.286 & 0.240 & 0.247 & 0.239 & 0.242 \\
\hline $\mathrm{S} 13$ & 0.276 & 0.205 & 0.177 & 0.242 & 0.287 & 0.264 & 0.219 & 0.255 & 0.248 & 0.272 & 0.334 & 0.306 & 0.315 & 0.305 & 0.308 \\
\hline $\mathrm{S} 14$ & 0.256 & 0.194 & 0.252 & 0.166 & 0.293 & 0.278 & 0.238 & 0.247 & 0.233 & 0.262 & 0.319 & 0.282 & 0.288 & 0.279 & 0.284 \\
\hline $\mathrm{S} 21$ & 0.314 & 0.217 & 0.232 & 0.238 & 0.225 & 0.279 & 0.246 & 0.297 & 0.285 & 0.216 & 0.279 & 0.240 & 0.242 & 0.238 & 0.242 \\
\hline $\mathrm{S} 22$ & 0.291 & 0.227 & 0.259 & 0.249 & 0.315 & 0.215 & 0.240 & 0.282 & 0.271 & 0.266 & 0.302 & 0.269 & 0.277 & 0.266 & 0.270 \\
\hline $\mathrm{S} 23$ & 0.245 & 0.185 & 0.211 & 0.201 & 0.270 & 0.243 & 0.156 & 0.243 & 0.229 & 0.292 & 0.354 & 0.326 & 0.333 & 0.318 & 0.325 \\
\hline $\mathrm{S} 24$ & 0.262 & 0.188 & 0.221 & 0.216 & 0.313 & 0.259 & 0.204 & 0.198 & 0.267 & 0.192 & 0.240 & 0.213 & 0.217 & 0.212 & 0.214 \\
\hline $\mathrm{S} 31$ & 0.245 & 0.180 & 0.194 & 0.189 & 0.275 & 0.215 & 0.195 & 0.241 & 0.176 & 0.242 & 0.265 & 0.228 & 0.234 & 0.225 & 0.224 \\
\hline $\mathrm{S} 32$ & 0.223 & 0.159 & 0.171 & 0.169 & 0.261 & 0.205 & 0.167 & 0.218 & 0.227 & 0.155 & 0.249 & 0.204 & 0.206 & 0.198 & 0.201 \\
\hline S33 & 0.274 & 0.202 & 0.241 & 0.217 & 0.294 & 0.263 & 0.211 & 0.236 & 0.248 & 0.241 & 0.239 & 0.273 & 0.280 & 0.274 & 0.276 \\
\hline S41 & 0.253 & 0.172 & 0.180 & 0.173 & 0.263 & 0.208 & 0.183 & 0.203 & 0.222 & 0.209 & 0.273 & 0.179 & 0.259 & 0.219 & 0.221 \\
\hline $\mathrm{S} 42$ & 0.250 & 0.171 & 0.188 & 0.172 & 0.264 & 0.202 & 0.187 & 0.207 & 0.213 & 0.210 & 0.270 & 0.250 & 0.183 & 0.219 & 0.218 \\
\hline S43 & 0.237 & 0.166 & 0.169 & 0.161 & 0.250 & 0.194 & 0.172 & 0.192 & 0.203 & 0.186 & 0.265 & 0.212 & 0.222 & 0.166 & 0.226 \\
\hline S44 & 0.230 & 0.160 & 0.163 & 0.160 & 0.243 & 0.188 & 0.173 & 0.188 & 0.201 & 0.184 & 0.254 & 0.204 & 0.211 & 0.219 & 0.163 \\
\hline
\end{tabular}


Table 7. Relevance and Impact between Criteria after Integration.

\begin{tabular}{lccccc}
\hline No. & Criteria & $\boldsymbol{D}_{\boldsymbol{i}}$ & $\boldsymbol{R}_{\boldsymbol{j}}$ & $\boldsymbol{D}_{\boldsymbol{i}}+\boldsymbol{R}_{\boldsymbol{j}}$ & $\boldsymbol{D}_{\boldsymbol{i}}-\boldsymbol{R}_{\boldsymbol{j}}$ \\
\hline S11 & Product Life Cycle & 3.908 & 3.131 & 7.039 & 0.777 \\
S12 & Regulatory Certification & 1.499 & 0.476 & 1.975 & 1.023 \\
S13 & Validate Goal Market & 3.411 & 1.256 & 4.668 & 2.155 \\
S14 & Sales Forecast & 3.511 & 1.001 & 4.512 & 2.510 \\
S21 & Product Quality Attributes & 3.131 & 3.928 & 7.059 & -0.797 \\
S22 & Product Pricing & 3.782 & 1.892 & 5.674 & 1.890 \\
S23 & After-Sales Service & 3.178 & 0.997 & 4.175 & 2.181 \\
S24 & Product Quality Rate & 1.340 & 1.863 & 3.203 & -0.522 \\
S31 & Manufacturing Capacity & 1.954 & 2.310 & 4.264 & -0.356 \\
S32 & Equipment Capacity & 0.737 & 1.815 & 2.552 & -1.078 \\
S33 & New Product Attributes & 2.663 & 3.992 & 6.655 & -1.329 \\
S41 & High Impact Test & 1.048 & 2.673 & 3.721 & -1.626 \\
S42 & Writing Durability & 1.251 & 2.739 & 3.990 & -1.488 \\
S43 & High and Low Temperature Test & 0.978 & 2.397 & 3.375 & -1.419 \\
S44 & High Temperature and High Humidity Test & 0.727 & 2.648 & 3.374 & -1.921 \\
\hline
\end{tabular}

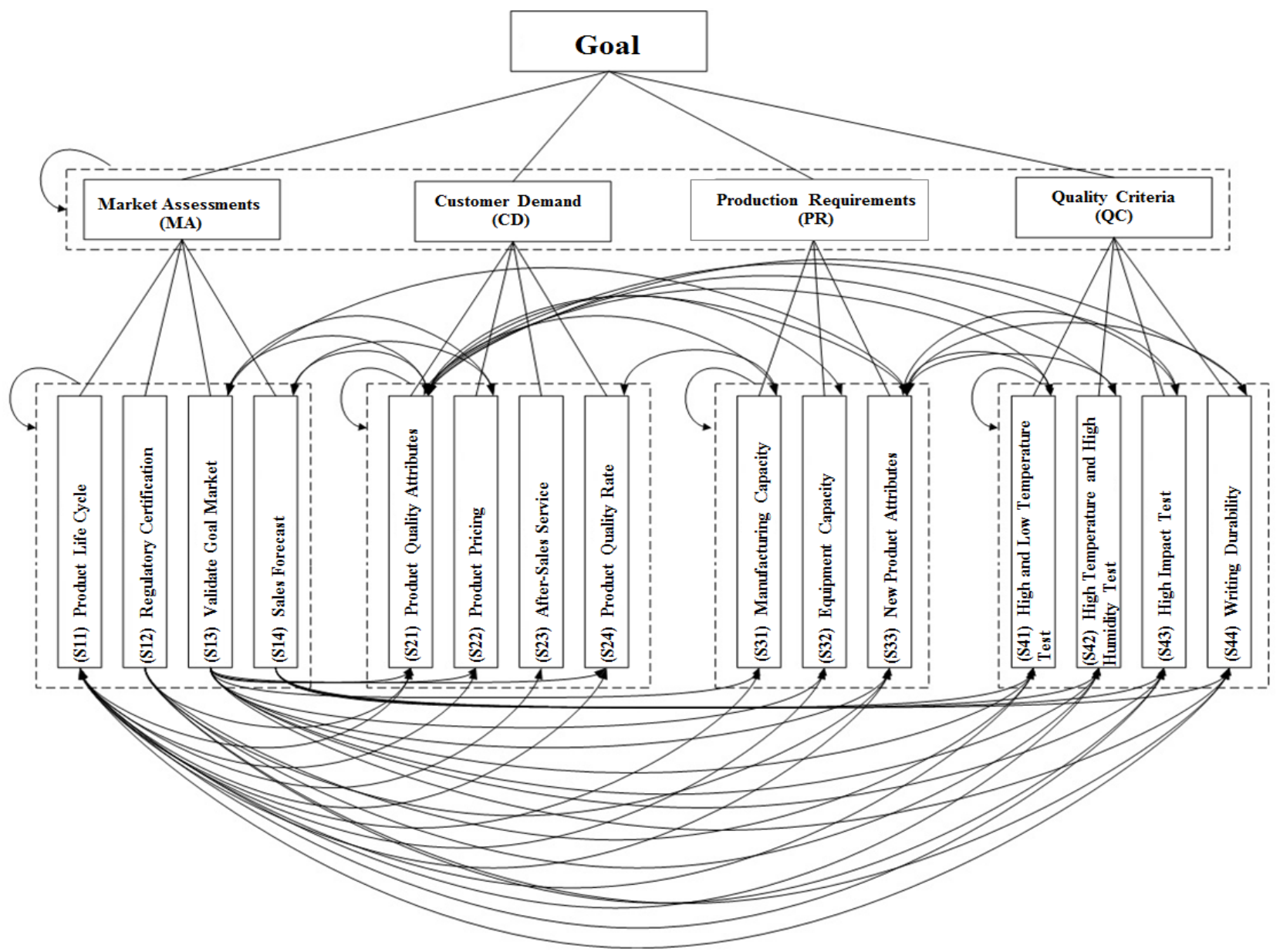

Figure 2. TFT-LCD NPD Performance Evaluation Model. 


\subsection{FANP}

DEMATEL is employed to calculate the relevance and impact between performance evaluation indices for TFT-LCD touch panel new product development; after establishing the structural relationship of criterion, this step applies FANP as multi-criteria decision making analysis. The ANP questionnaire is designed with a nine-point Liker scale proposed by Saaty (1980) for issuance to management, marketing, and manufacturing department supervisors for new product development performance evaluation. The weights are calculated through paired comparison of aspect and criteria to find the key success factors to new product development, providing critical reference for decision makers in the process of decision making.

\subsubsection{Forming Pair-Wise Comparison Matrices}

In this step, DEMATEL computation establishes the network structure including the relevance between enterprise goal, aspect-to-aspect and criterion-to-criterion. This structure becomes the foundation of the FANP to design a nine-point Likert scale questionnaire and conduct expert criteria evaluation to form pair-wise comparison matrices through questionnaire results.

\subsubsection{Constructing Fuzzy Positive Matrices}

Fuzzy theory converts each pair-wise comparison matrix into linguistic variables that substitutes the paired matrix into Equation (8) for calculation, which is concurrently denoted by fuzzy triangular number to become fuzzy positive matrices.

\subsubsection{Integrating the Opinions of Decision Makers}

The step above fuzzifies the paired matrices from the six experts. The geometric means consolidates the fuzzification weights of experts in this step, which is presented as a triangular fuzz number, as shown in Table 8.

Table 8. Fuzzy Pair-wise Comparison Matrix.

\begin{tabular}{ccccc}
\hline \multirow{2}{*}{ Aspects } & $\begin{array}{c}\text { Market } \\
\text { Assessments }\end{array}$ & $\begin{array}{c}\text { Customer } \\
\text { Demands }\end{array}$ & $\begin{array}{c}\text { Product } \\
\text { Requirements }\end{array}$ & $\begin{array}{c}\text { Quality } \\
\text { Criteria }\end{array}$ \\
\hline Market Assessments & $(1.00,1.00,1.00)$ & $(1.00,1.104,1.17)$ & $(0.438,0.575,0.906)$ & $(0.438,0.635,1.060)$ \\
\hline Customer Demands & $(0.855,0.906,1.007)$ & $(1.00,1.00,1.00)$ & $(0.492,0.599,0.820)$ & $(0.624,0.743,1.00)$ \\
\hline Product Requirements & $(1.104,1.739,2.284)$ & $(1.219,1.669,2.034)$ & $(1.00,1.00,1.00)$ & $(0.534,0.673,1.00)$ \\
\hline Quality Criteria & $(0.944,1.575,2.284)$ & $(1.00,1.346,1.601)$ & $(1.00,1.486,1.873)$ & $(1.00,1.00,1.00)$ \\
\hline
\end{tabular}

\subsubsection{Defuzzification}

This phase defuzzifies the triangular fuzzy number and carries out defuzzification through theory proposed by Chen [53], as shown in Table 9. 
Table 9. Pair-wise Comparison Matrix after Defuzzification.

\begin{tabular}{ccccc}
\hline Aspects & $\begin{array}{c}\text { Market } \\
\text { Assessments }\end{array}$ & $\begin{array}{c}\text { Customers } \\
\text { Demand }\end{array}$ & $\begin{array}{c}\text { Product } \\
\text { Requirements }\end{array}$ & $\begin{array}{c}\text { Quality } \\
\text { Criteria }\end{array}$ \\
\hline Market Assessments & 1.00 & 1.091 & 0.640 & 0.711 \\
Customer Demands & 0.920 & 1.00 & 0.637 & 0.789 \\
Product Requirements & 1.709 & 1.640 & 1.00 & 0.736 \\
Quality Criteria & 1.601 & 1.316 & 1.453 & 1.000 \\
\hline
\end{tabular}

\subsubsection{Examining the Consistency}

A defuzzified matrix requires consistency and eigenvector calculation. The study applies the concept proposed by Saaty to assume the C.R. value smaller than 0.1 and test whether or not the matrix reaches consistency in expert rating. Table 10 shows the consolidated expert consistency test on the four aspects.

Table 10. Eigenvectors and Consistency Test for Aspects.

\begin{tabular}{cccccc}
\hline Aspects & $\begin{array}{c}\text { Market } \\
\text { Assessments }\end{array}$ & $\begin{array}{c}\text { Customer } \\
\text { Demands }\end{array}$ & $\begin{array}{c}\text { Product } \\
\text { Requirements }\end{array}$ & $\begin{array}{c}\text { Quality } \\
\text { Criteria }\end{array}$ & Weights \\
\hline Market Assessments & 0.230 & 0.131 & 0.381 & 0.273 & 0.254 \\
Customer Demands & 0.379 & 0.203 & 0.114 & 0.133 & 0.207 \\
Product Requirements & 0.210 & 0.392 & 0.330 & 0.395 & 0.332 \\
Quality Criteria & 0.181 & 0.274 & 0.174 & 0.200 & 0.207 \\
\hline
\end{tabular}

Notes: $\lambda_{\max }=40.236 ;$ C.I. $=0.079 ;$ R.I. $=0.9 ;$ C.R. $=0.087$.

\subsubsection{Forming Initial Super-Matrix}

After validating the consistency in each matrix, eigenvector is calculated by placing each paired eigenvectors under the matrix into super matrix. Prior to calculating super matrix, compiling all pair-wise comparison matrices into un-weighed super matrix is required, as shown in Table 11. 
Table 11. Initial Super-matrix.

\begin{tabular}{|c|c|c|c|c|c|c|c|c|c|c|c|c|c|c|c|c|c|c|c|}
\hline No. & MA & CD & PR & QC & S11 & S12 & $\mathrm{S} 13$ & S14 & $\mathbf{S 2 1}$ & $\mathbf{S 2 2}$ & $\mathbf{S 2 3}$ & S24 & S31 & S32 & S33 & S41 & S42 & S43 & S44 \\
\hline MA & 0.157 & 0.239 & 0.239 & 0.239 & 0 & 0 & 0 & 0 & 0 & 0 & 0 & 0 & 0 & 0 & 0 & 0 & 0 & 0 & 0 \\
\hline $\mathrm{CD}$ & 0.580 & 0.508 & 0.508 & 0.508 & 0 & 0 & 0 & 0 & 0 & 0 & 0 & 0 & 0 & 0 & 0 & 0 & 0 & 0 & 0 \\
\hline PR & 0.165 & 0.188 & 0.188 & 0.188 & 0 & 0 & 0 & 0 & 0 & 0 & 0 & 0 & 0 & 0 & 0 & 0 & 0 & 0 & 0 \\
\hline $\mathrm{QC}$ & 0.098 & 0.065 & 0.065 & 0.065 & 0 & 0 & 0 & 0 & 0 & 0 & 0 & 0 & 0 & 0 & 0 & 0 & 0 & 0 & 0 \\
\hline $\mathrm{S} 11$ & 0 & 0 & 0 & 0 & 0.575 & 0.254 & 0.254 & 0.254 & 0 & 0 & 0 & 0 & 0 & 0 & 0 & 0 & 0 & 0 & 0 \\
\hline $\mathrm{S} 12$ & 0 & 0 & 0 & 0 & 0.087 & 0.207 & 0.207 & 0.207 & 0 & 0 & 0 & 0 & 0 & 0 & 0 & 0 & 0 & 0 & 0 \\
\hline $\mathrm{S} 13$ & 0 & 0 & 0 & 0 & 0.184 & 0.332 & 0.332 & 0.332 & 0 & 0 & 0 & 0 & 0 & 0 & 0 & 0 & 0 & 0 & 0 \\
\hline S14 & 0 & 0 & 0 & 0 & 0.155 & 0.207 & 0.207 & 0.207 & 0 & 0 & 0 & 0 & 0 & 0 & 0 & 0 & 0 & 0 & 0 \\
\hline $\mathrm{S} 21$ & 0 & 0 & 0 & 0 & 0.491 & 0.489 & 0.489 & 0.566 & 0.469 & 0.489 & 0.489 & 0.489 & 0 & 0 & 0 & 0 & 0 & 0 & 0 \\
\hline $\mathrm{S} 22$ & 0 & 0 & 0 & 0 & 0.167 & 0.138 & 0.138 & 0.212 & 0.181 & 0.138 & 0.138 & 0.138 & 0 & 0 & 0 & 0 & 0 & 0 & 0 \\
\hline S23 & 0 & 0 & 0 & 0 & 0.066 & 0.067 & 0.067 & 0.101 & 0.082 & 0.067 & 0.067 & 0.067 & 0 & 0 & 0 & 0 & 0 & 0 & 0 \\
\hline S24 & 0 & 0 & 0 & 0 & 0.277 & 0.306 & 0.306 & 0.121 & 0.268 & 0.306 & 0.306 & 0.306 & 0 & 0 & 0 & 0 & 0 & 0 & 0 \\
\hline S31 & 0 & 0 & 0 & 0 & 0.236 & 0.183 & 0.272 & 0.154 & 0.352 & 0.214 & 0.258 & 0.183 & 0.388 & 0.183 & 0.183 & 0 & 0 & 0 & 0 \\
\hline $\mathrm{S} 32$ & 0 & 0 & 0 & 0 & 0.156 & 0.142 & 0.285 & 0.112 & 0.300 & 0.169 & 0.164 & 0.142 & 0.170 & 0.142 & 0.142 & 0 & 0 & 0 & 0 \\
\hline S33 & 0 & 0 & 0 & 0 & 0.608 & 0.676 & 0.444 & 0.734 & 0.347 & 0.617 & 0.578 & 0.676 & 0.442 & 0.676 & 0.676 & 0 & 0 & 0 & 0 \\
\hline S41 & 0 & 0 & 0 & 0 & 0.324 & 0.323 & 0.249 & 0.308 & 0.229 & 0.308 & 0.312 & 0.341 & 0.341 & 0.341 & 0.310 & 0.341 & 0.341 & 0.341 & 0.341 \\
\hline S42 & 0 & 0 & 0 & 0 & 0.267 & 0.266 & 0.223 & 0.195 & 0.343 & 0.277 & 0.279 & 0.331 & 0.331 & 0.331 & 0.273 & 0.331 & 0.331 & 0.331 & 0.331 \\
\hline S43 & 0 & 0 & 0 & 0 & 0.219 & 0.228 & 0.281 & 0.275 & 0.246 & 0.209 & 0.215 & 0.171 & 0.171 & 0.171 & 0.226 & 0.171 & 0.171 & 0.171 & 0.171 \\
\hline $\mathrm{S} 44$ & 0 & 0 & 0 & 0 & 0.190 & 0.183 & 0.247 & 0.222 & 0.181 & 0.206 & 0.194 & 0.158 & 0.158 & 0.158 & 0.191 & 0.158 & 0.158 & 0.158 & 0.158 \\
\hline
\end{tabular}




\subsubsection{Obtaining the Priority of Total Weight for Evaluation}

First, sub-matrices with priority eigenvectors are combined to form an initial super-matrix. As it may not fit the column stochastic rule, normalize each column matrix to make a weighted super-matrix. Finally, use MATLAB to multiply the weighted super-matrix to make it converged. Final weights after normalization are shown in Table 12.

Table 12. Final weights after normalization.

\begin{tabular}{|c|c|c|c|c|}
\hline Aspects & Weights & Criteria & Total Weights & Ranking \\
\hline \multirow{4}{*}{$\begin{array}{c}\text { Market } \\
\text { Assessments }\end{array}$} & \multirow{4}{*}{0.221} & Product Life Cycle & 0.0774 & 5 \\
\hline & & Regulatory Certification & 0.0387 & 10 \\
\hline & & Validate Goal Market & 0.0608 & 6 \\
\hline & & Sales Forecast & 0.0442 & 7 \\
\hline \multirow{4}{*}{$\begin{array}{l}\text { Customer } \\
\text { Demands }\end{array}$} & \multirow{4}{*}{0.524} & Product Quality Attributes & 0.2531 & 1 \\
\hline & & Product Pricing & 0.0812 & 4 \\
\hline & & After-Sales Service & 0.0409 & 9 \\
\hline & & Product Quality Rate & 0.1488 & 2 \\
\hline \multirow{3}{*}{$\begin{array}{c}\text { Product } \\
\text { Requirements }\end{array}$} & \multirow{3}{*}{0.183} & Manufacturing Capacity & 0.0439 & 8 \\
\hline & & Equipment Capacity & 0.0298 & 11 \\
\hline & & New Product Attributes & 0.1093 & 3 \\
\hline \multirow{4}{*}{$\begin{array}{l}\text { Quality } \\
\text { Criteria }\end{array}$} & \multirow{4}{*}{0.072} & High Impact Test & 0.0244 & 12 \\
\hline & & Writing Durability & 0.0236 & 13 \\
\hline & & High and Low Temperature Test & 0.0125 & 14 \\
\hline & & High Temperature and High Humidity Test & 0.0114 & 15 \\
\hline
\end{tabular}

It is inevitable that the market for TFT-LCD products is immense due to its wide scope of availability. Enterprises expand market share and increase self-competitiveness through developing new products, due to the massive funding invested by Taiwan TFT-LCD enterprises in NPD and the intense market competition worldwide, NPD strategy has become the key factor for enterprises to succeed with advantages. The purpose of this study aims to establish a Taiwan TF-LCD touch panel NPD performance evaluation model, which evaluate the NPD criteria while proposing to enterprises in order to drive enterprises to move forward. Table 12 shows the new product development performance evaluation model, which represents the weights of aspects to goal and the weights of criteria to goals. For aspects under goal, the customer's demand shows the highest weight with value of $52.4 \%$, implying that customer demand plays the most critical aspect factor to the success of NPD. Market assessment shows the second highest data with a weight of $22.1 \%$, implying that market assessment is the second order of priority in new NPD, followed by Product Development and Quality Criteria, with the order of weights $18.3 \%$ and $7.2 \%$, respectively. For criteria under goal, product quality attribute receive the highest weight of $25.31 \%$, suggesting that quality attribute is the criteria with priority consideration for new product development. The second highest value is product quality rate with a value of $14.88 \%$, suggesting that product quality rate is the criteria with second priority of consideration. The criteria with third priority of consideration are new product attributes, which value is $10.93 \%$. The criteria with fourth priority of consideration are product pricing, with the value $8.12 \%$. The criteria with fifth priority of consideration are product life cycle, with the value $7.77 \%$. 
Product quality attributes represent the stability of products and are also one of the reference indicators of customer purchase; if new products offer high quality attributes and high quality rate, product competitive competency can be increased and the cost of production can also be reduced, therefor effectively improving the production performance of NPD is critical. Moreover, the visible new product attributes highlight the product features, adding peculiarity and differentiation from previous products. The development of new products also relies on new technology and capital development while drawing more attention to price. Thus, product pricing is also a key criterion to developing new products; product life cycle implies the competiveness of enterprise in the market, and the longer the maturity period of product life cycle, the more advantageous it is for the enterprise. Therefore, the key factor to new product development lies on the product uniqueness and the value of market existence, which serve as the priority consideration required for NPD. On the contrary, the existing enterprises develop new products based on customer's demand and market forecast trends, which coincide with the study proposal of prioritizing customer's demand and market assessment, suggest the conformance of the model built by the study within a real situation, and that the model can be applied to new product development performance evaluation in order to assure the enterprises success in developing new products through a more effective approach.

\section{Conclusions}

The life cycle of products is inevitably shortened today's intensely competitive market, and it is particularly important for enterprises to successfully develop on-time new products. Companies now face survival issues that arise from competition from all over the world. Thus, correctly evaluating NPD performance will effectively improve the competitiveness of new products in the market, and hence extend the life cycle of new products. This study implements a NPD performance evaluation on the TFT-LCD industry in Taiwan. DEMATEL is employed to calculate the mutual impact between factors and to validate the casualty between factors. FANP is applied to find the key criteria that affect new product development performance. The results show that the customer's demand and market assessment are the key reference aspects of NPD, leading to production oriented to the customer's demand, as well as products with unique design and high market acceptance. In addition, product quality, product quality rate, new product attributes, product pricing, and product life cycle are all considered as having important roles as key reference criteria. Product uniqueness also affects the market value of products. A good product with competitiveness implies along product life cycle, while the verification of mutual impact between criteria indicates that a new product must be competitive to help drive enterprises with consistent progress. A performance evaluation model of NPD is built to find the key factors that increase the success rate of TFT-LCD touch panel industry, and thus improve the competitiveness of Taiwan's TFT-LCD touch panel industry in international markets.

\section{Author Contributions}

Wen-Chin Chen and Hui-Pin Chang constructed the model and designed the computer code. All authors carried out data analysis, discussed the results and wrote the paper. 


\section{Conflicts of Interest}

The authors declare no conflict of interest.

\section{Appendix}

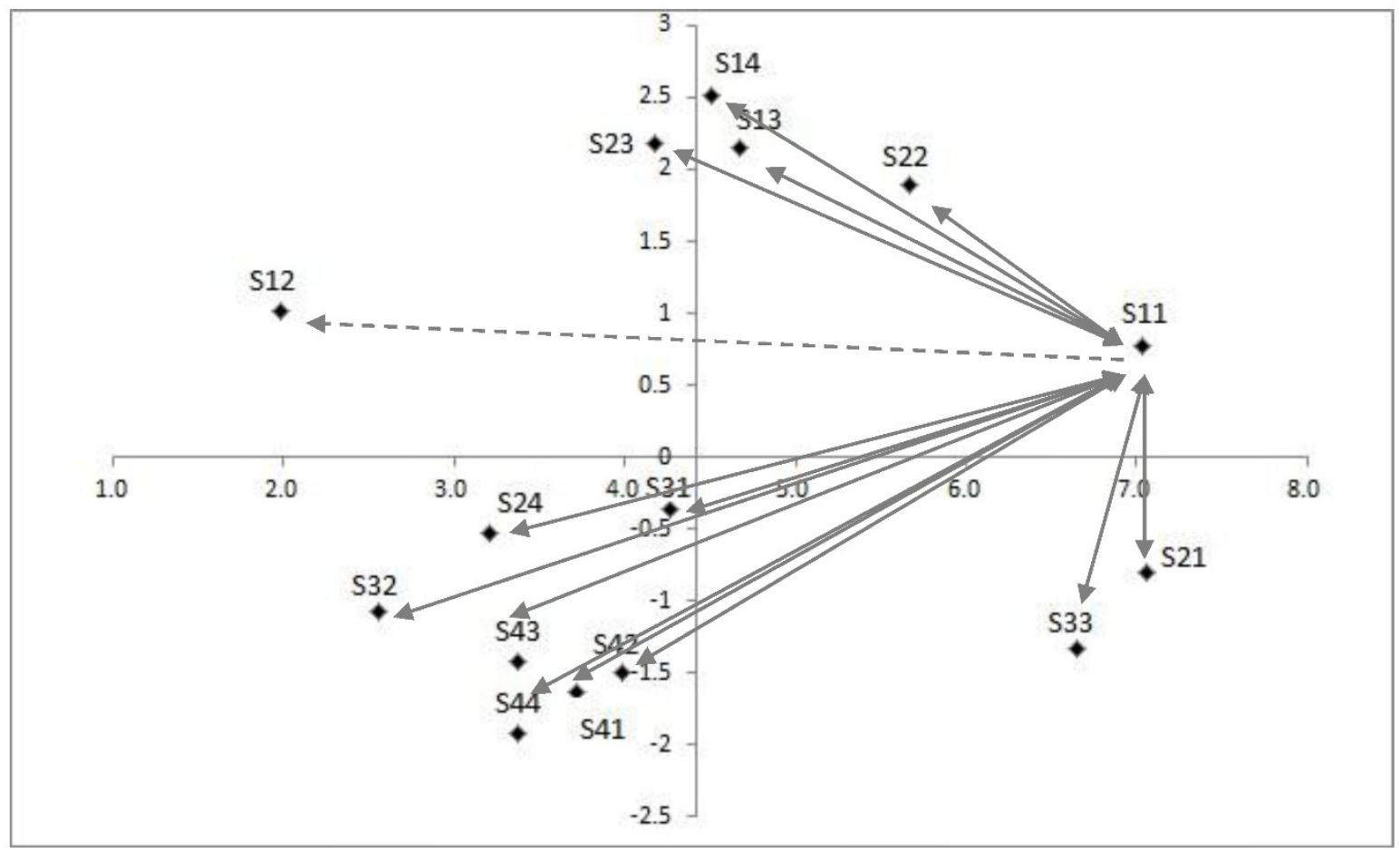

Figure A1. Casual Diagram between S11 and Other Criteria.

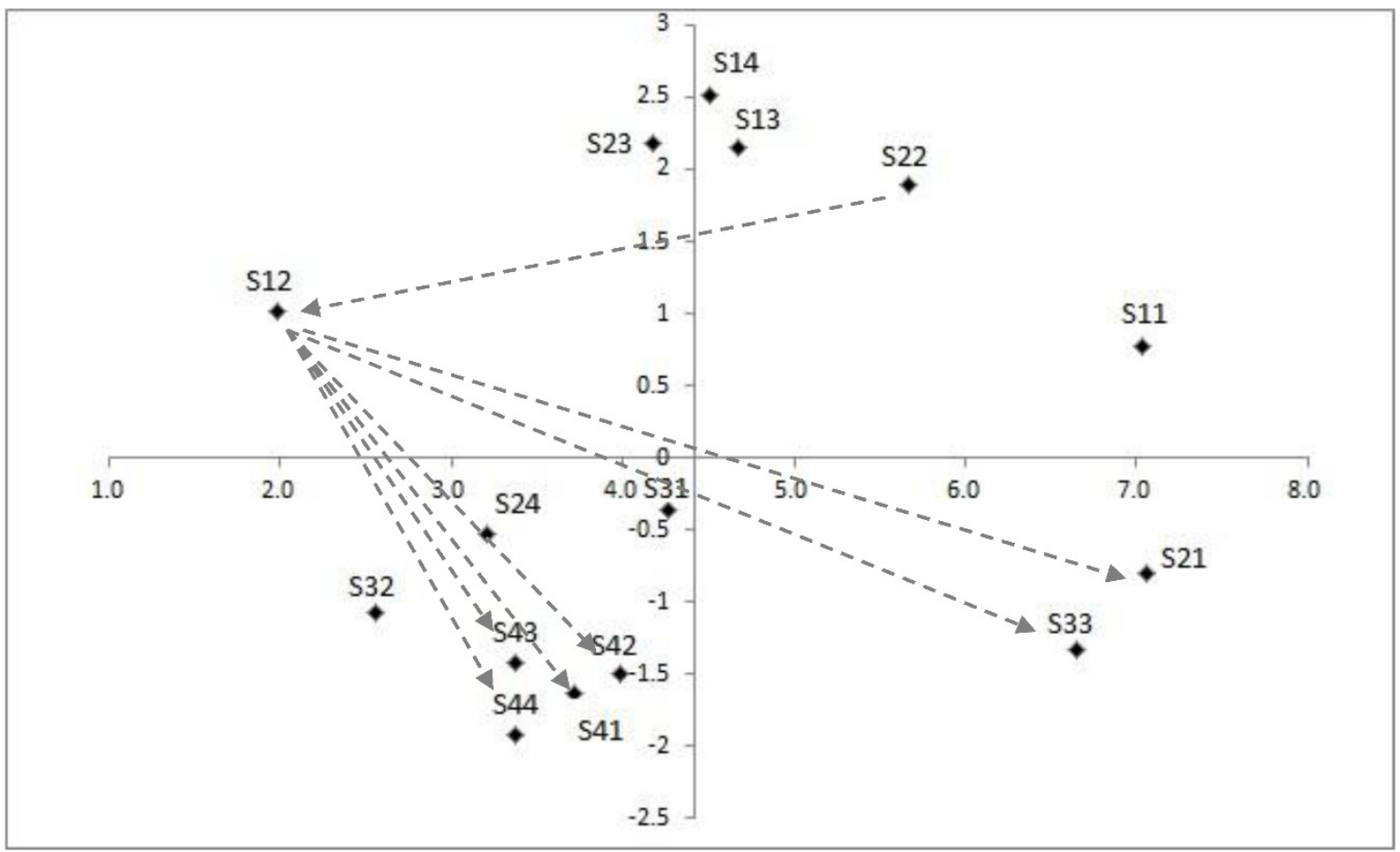

Figure A2. Casual Diagram between S12 and Other Criteria. 


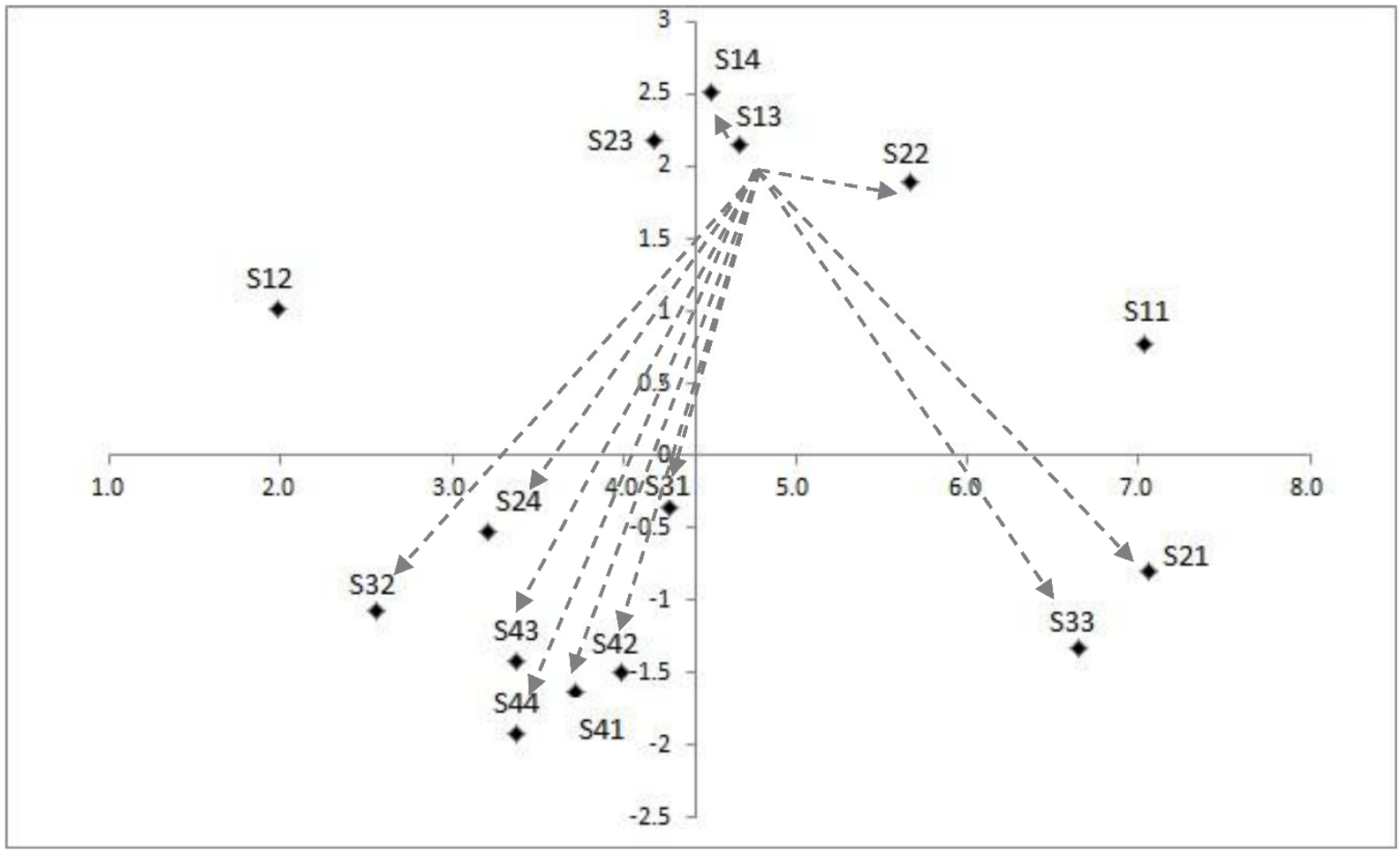

Figure A3. Casual Diagram between S13 and Other Criteria.

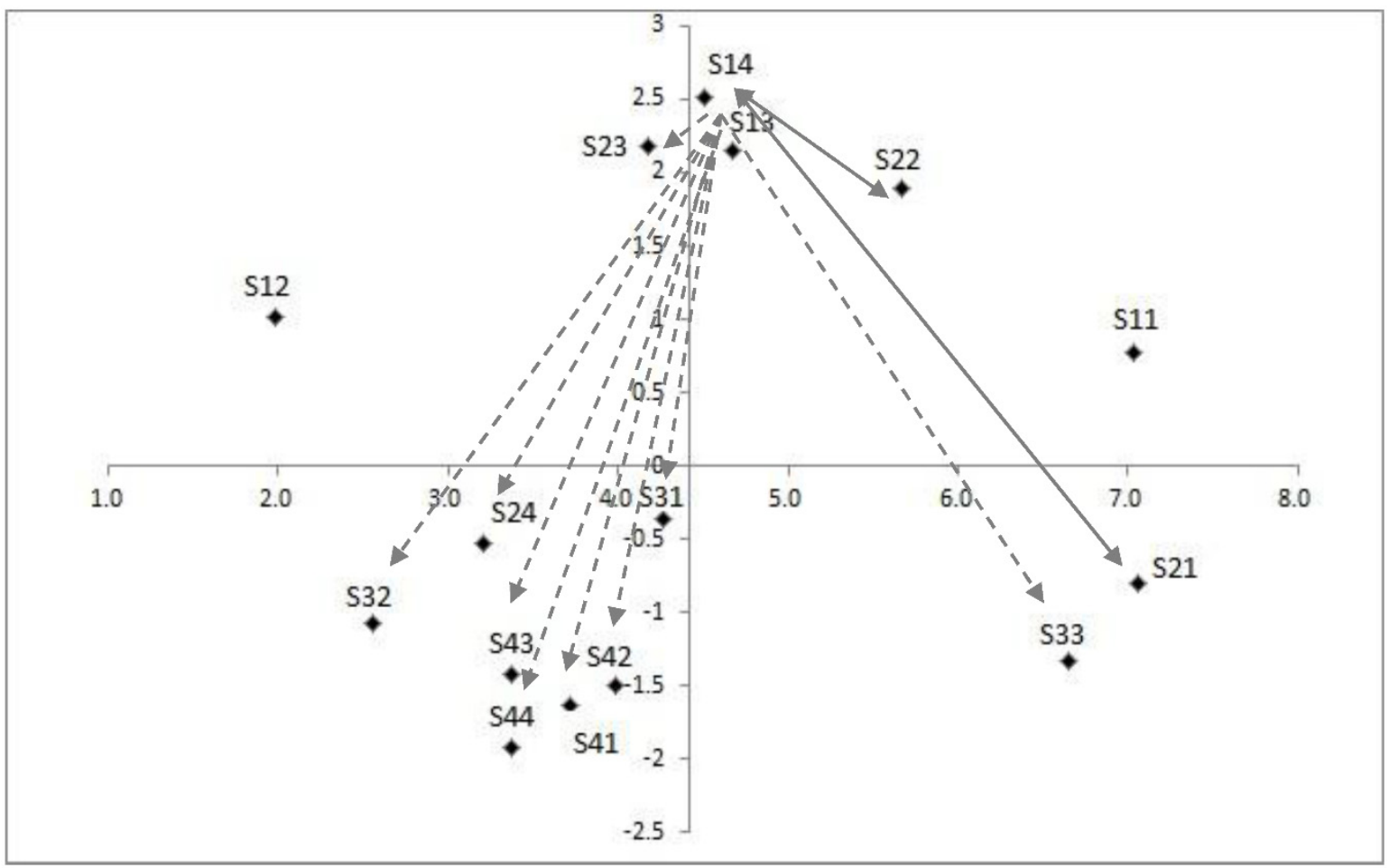

Figure A4. Casual Diagram between S14 and Other Criteria. 


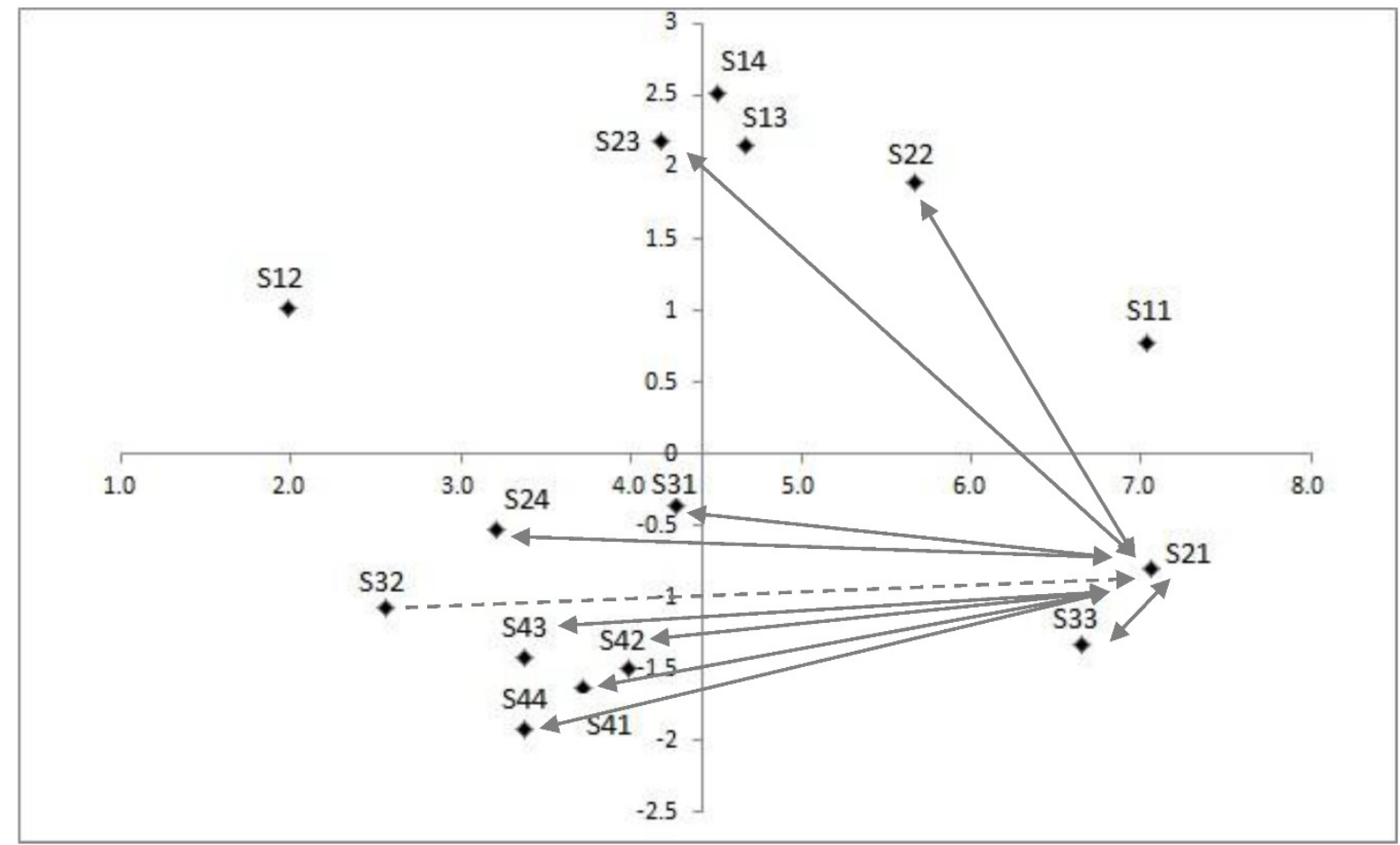

Figure A5. Casual Diagram between S21 and Other Criteria.

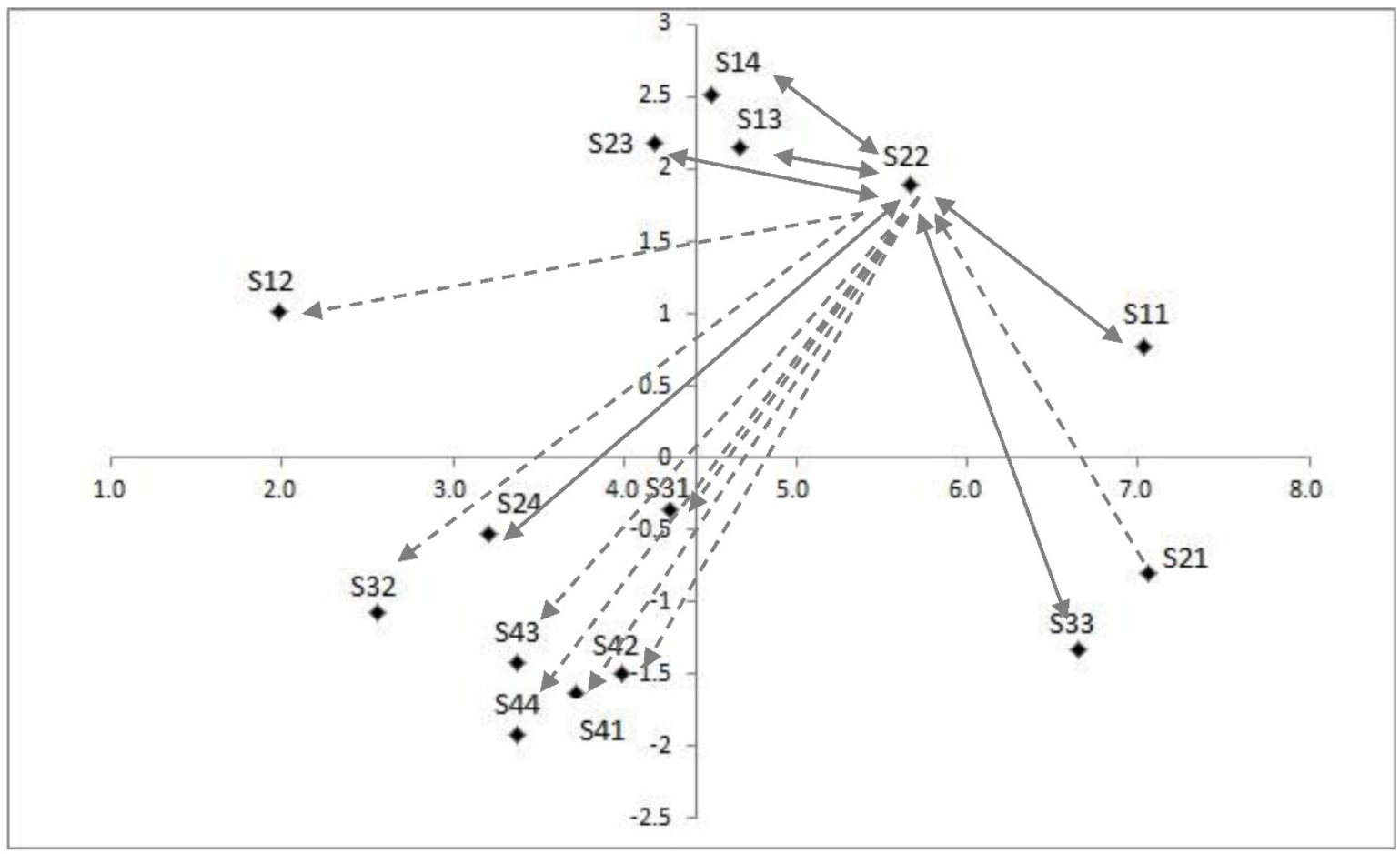

Figure A6. Casual Diagram between S22 and Other Criteria. 


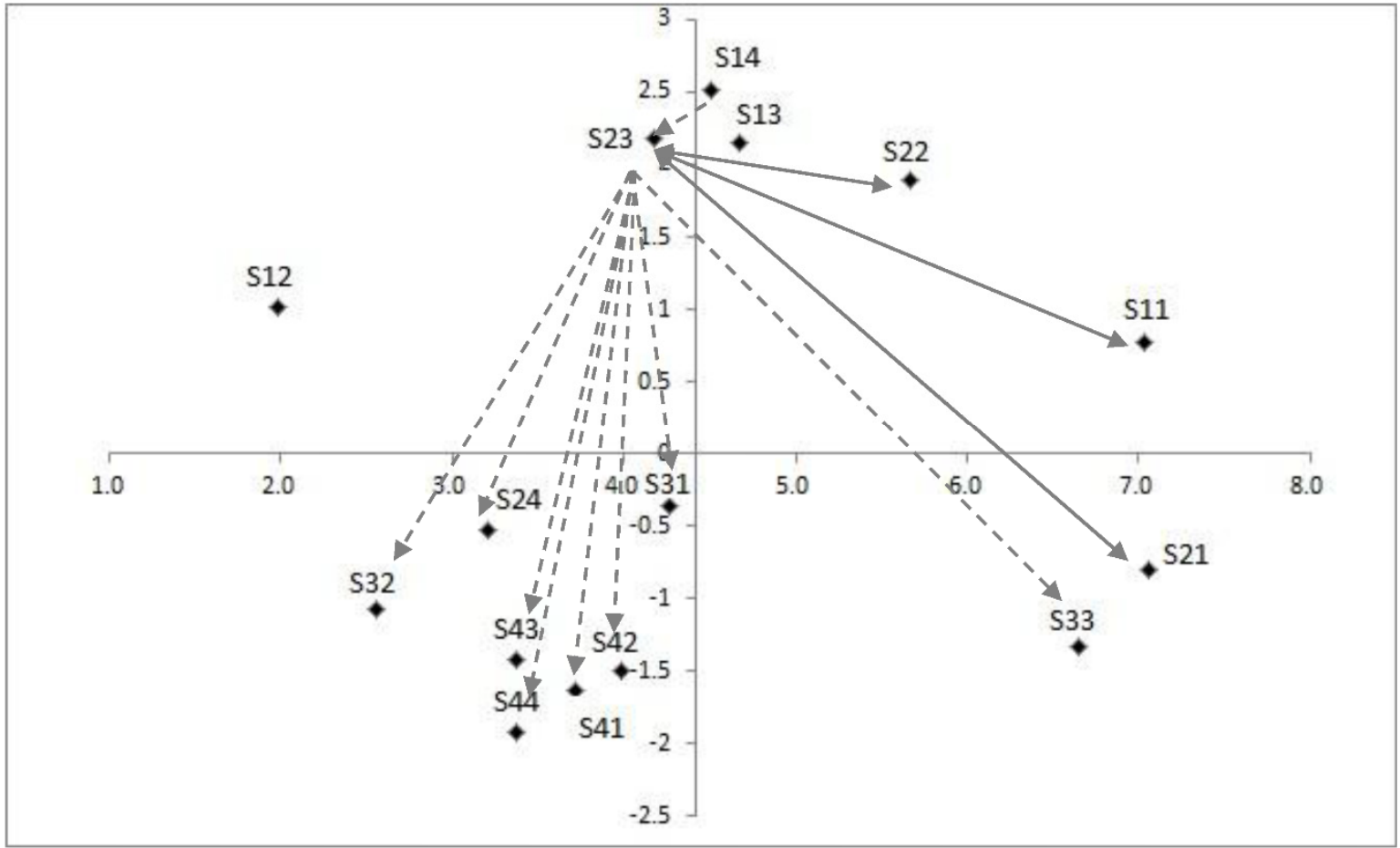

Figure A7. Casual Diagram between S23 and Other Criteria.

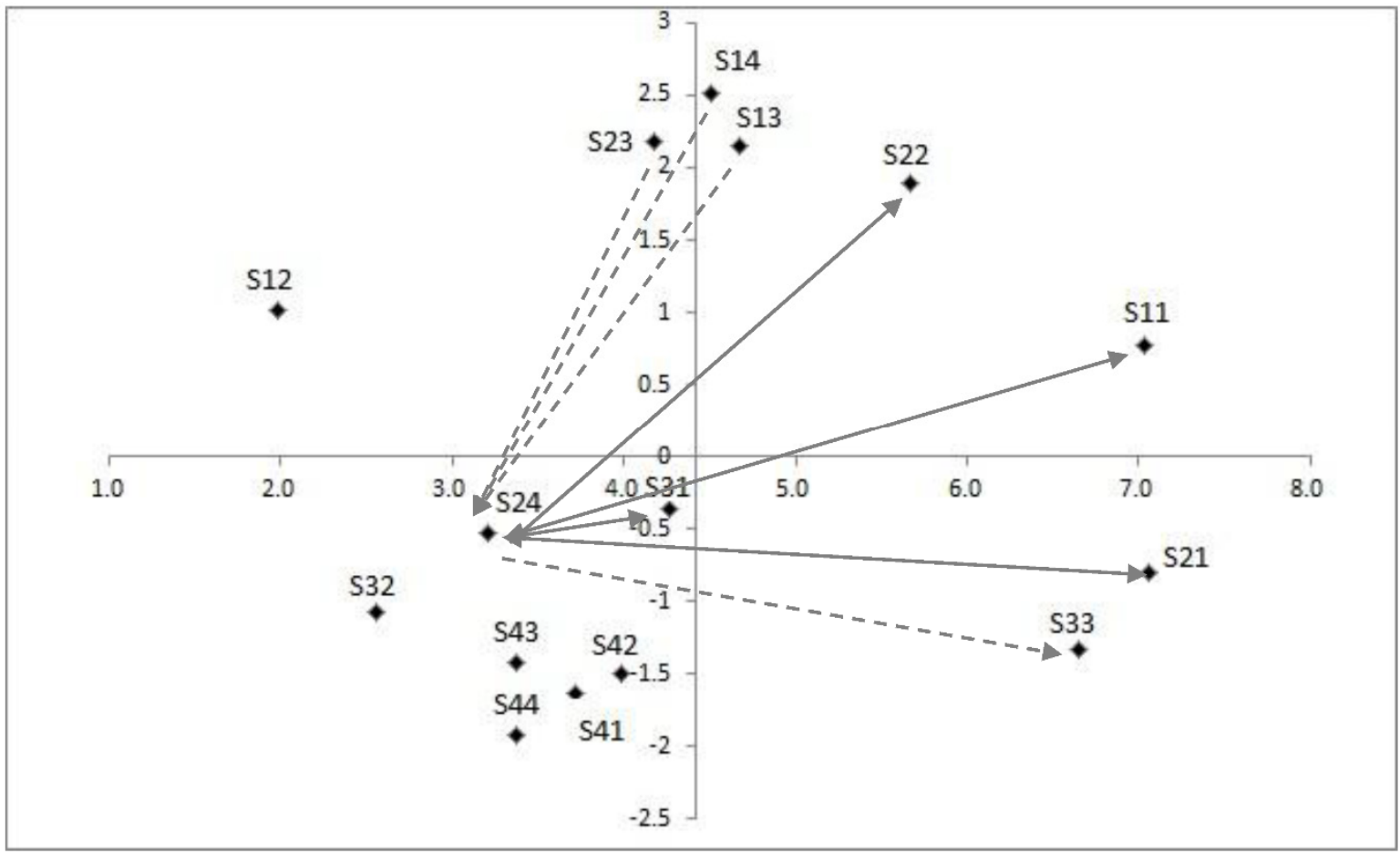

Figure A8. Casual Diagram between S24 and Other Criteria. 


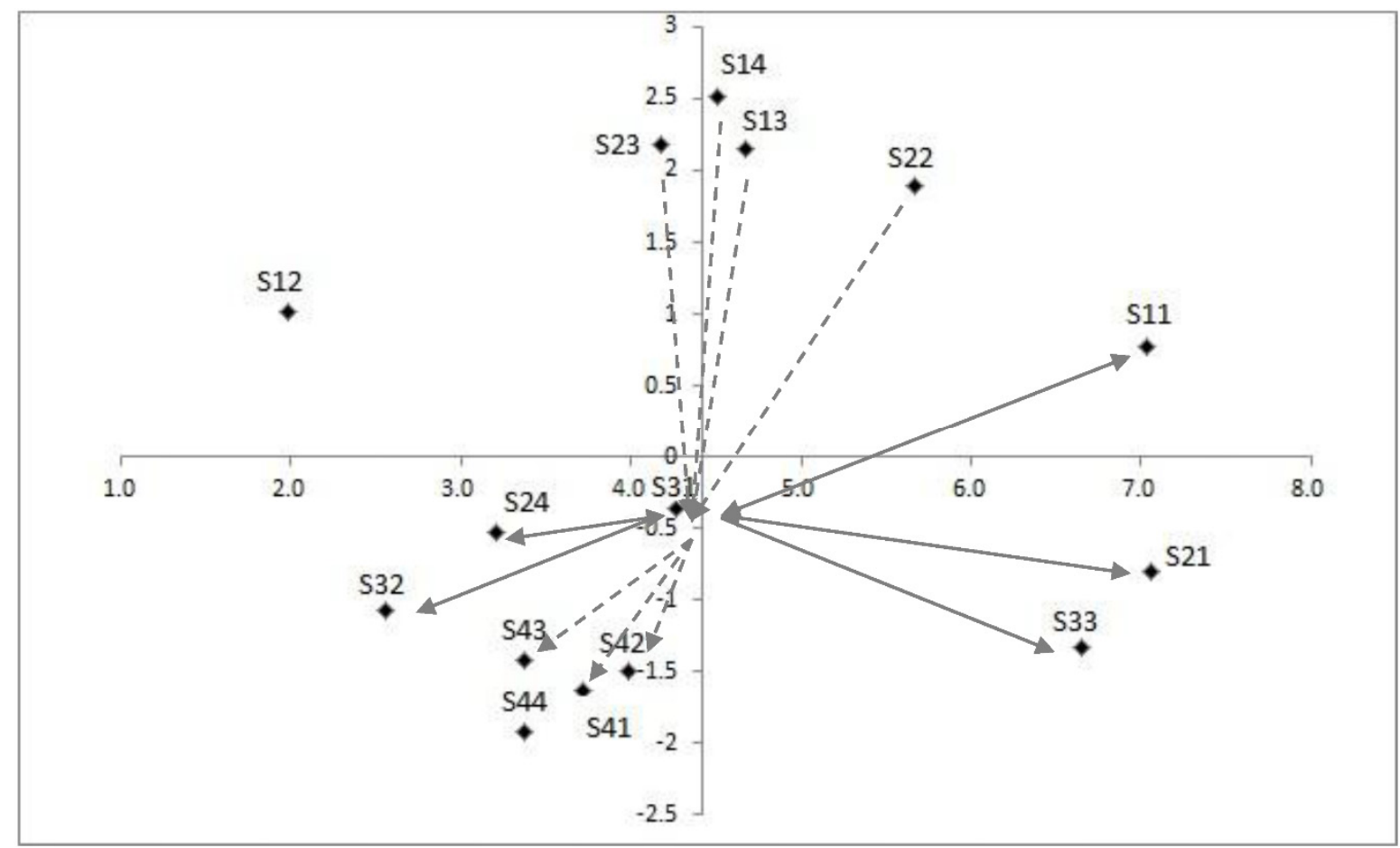

Figure A9. Casual Diagram between S31 and Other Criteria.

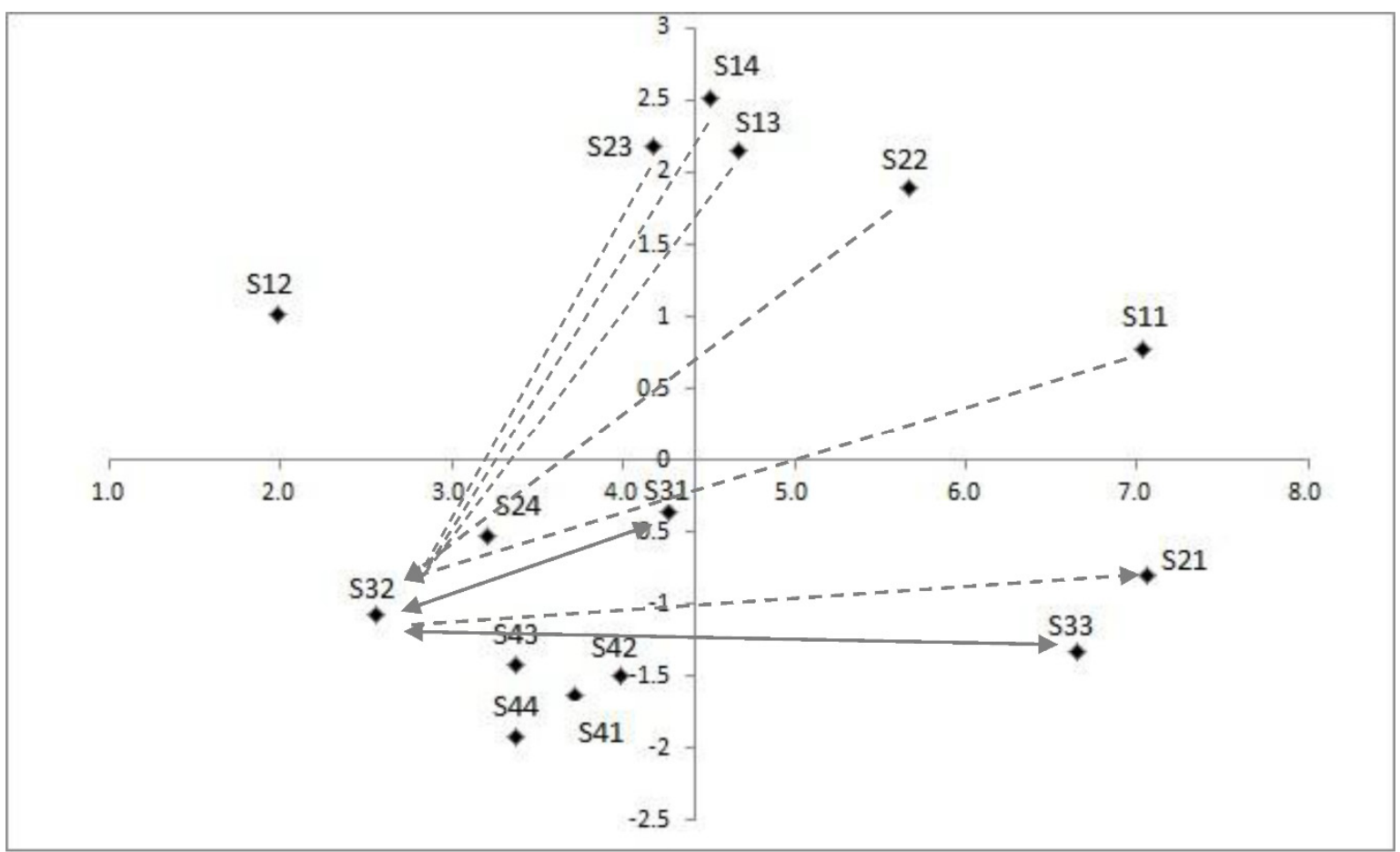

Figure A10. Casual Diagram between S32 and Other Criteria. 


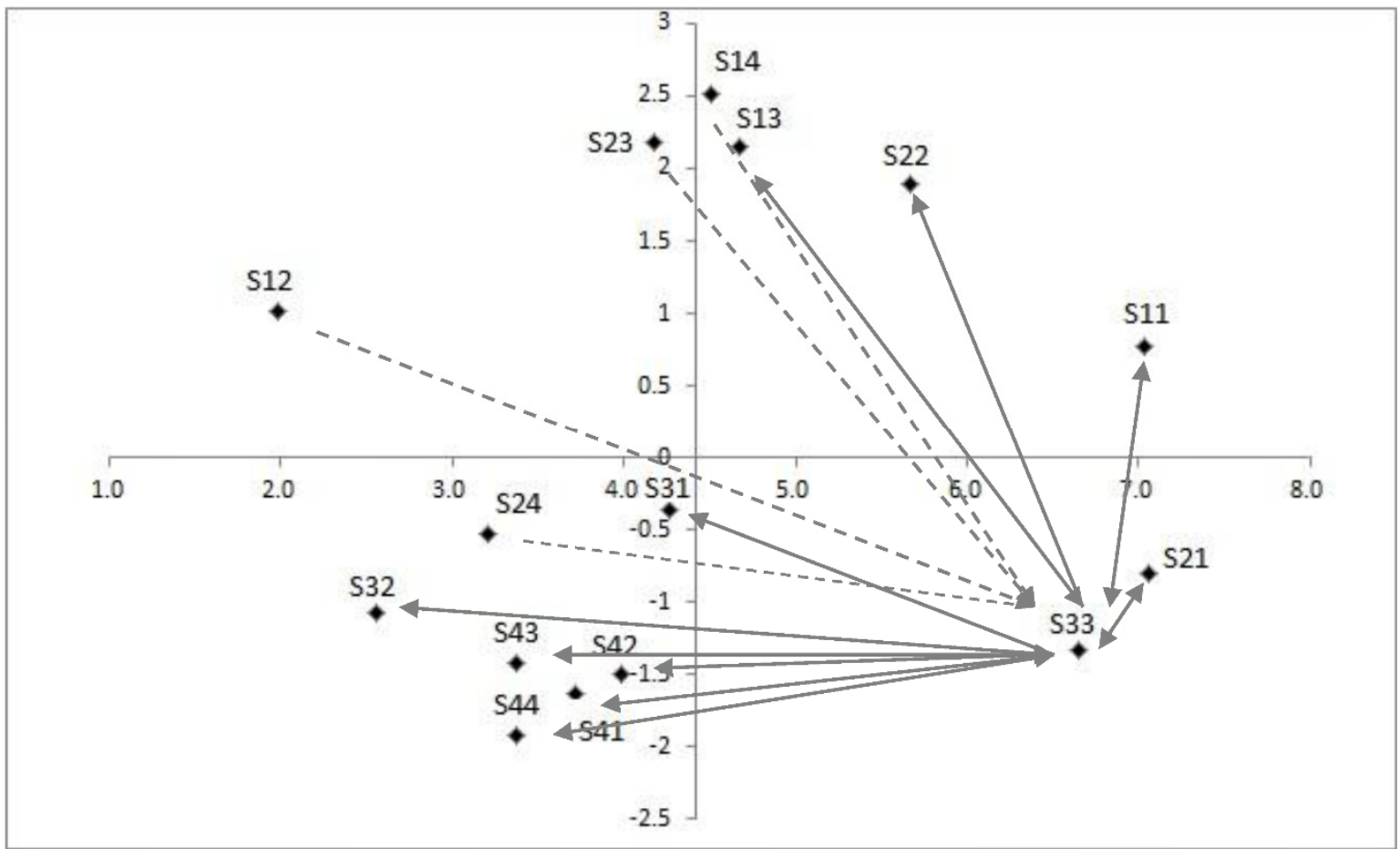

Figure A11. Casual Diagram between S33 and Other Criteria.

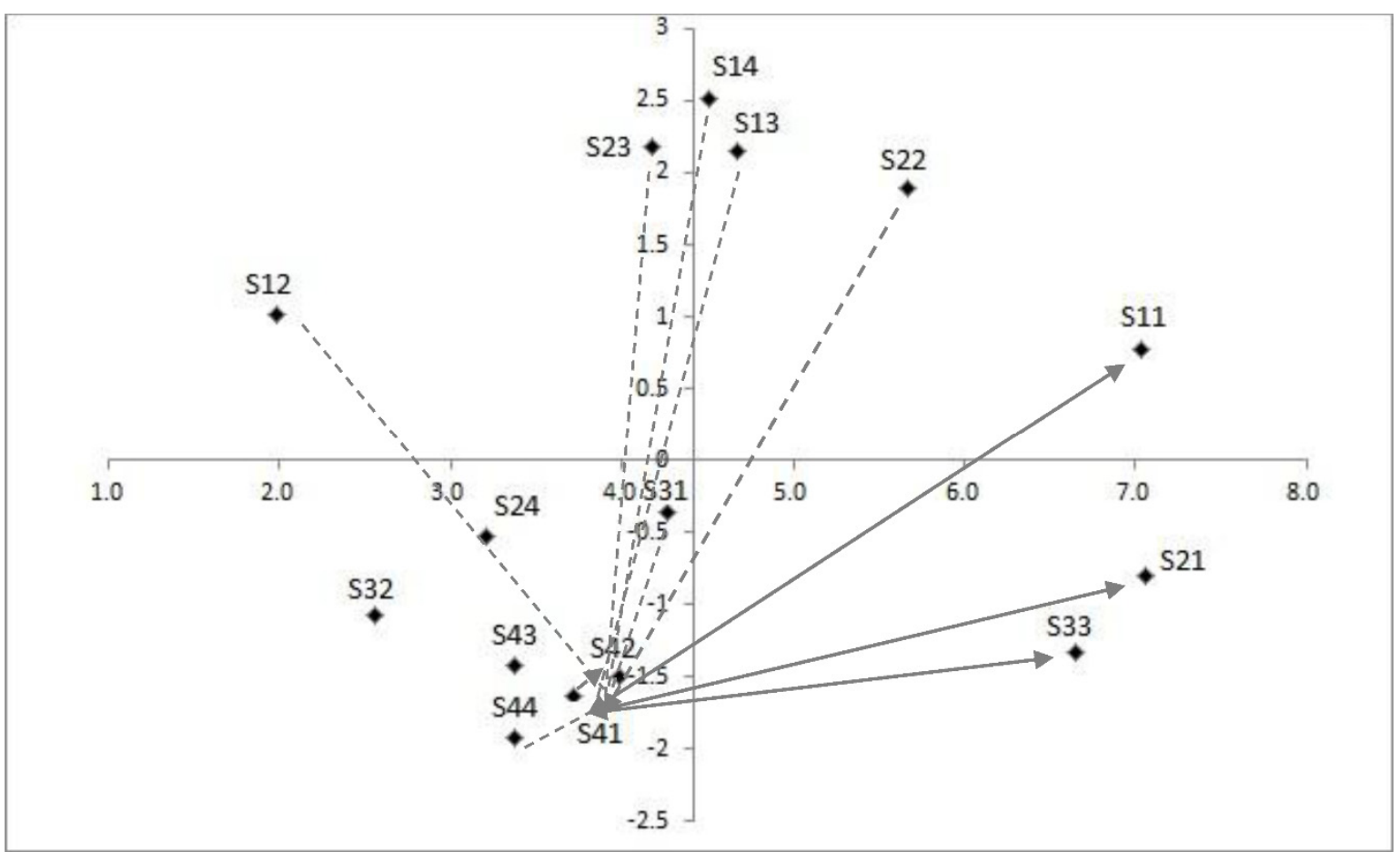

Figure A12. Casual Diagram between S41 and Other Criteria. 


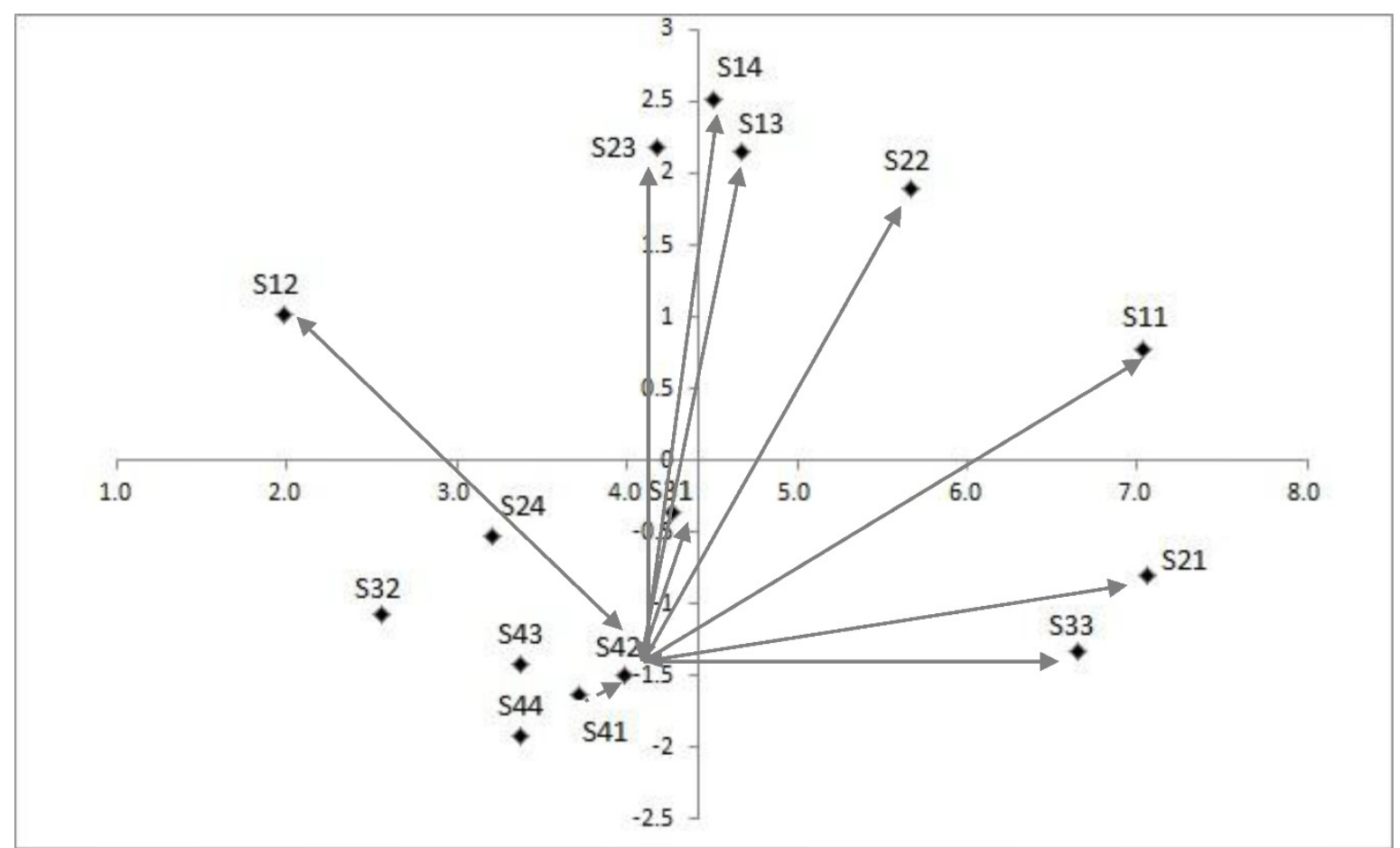

Figure A13. Casual Diagram between S42 and Other Criteria.

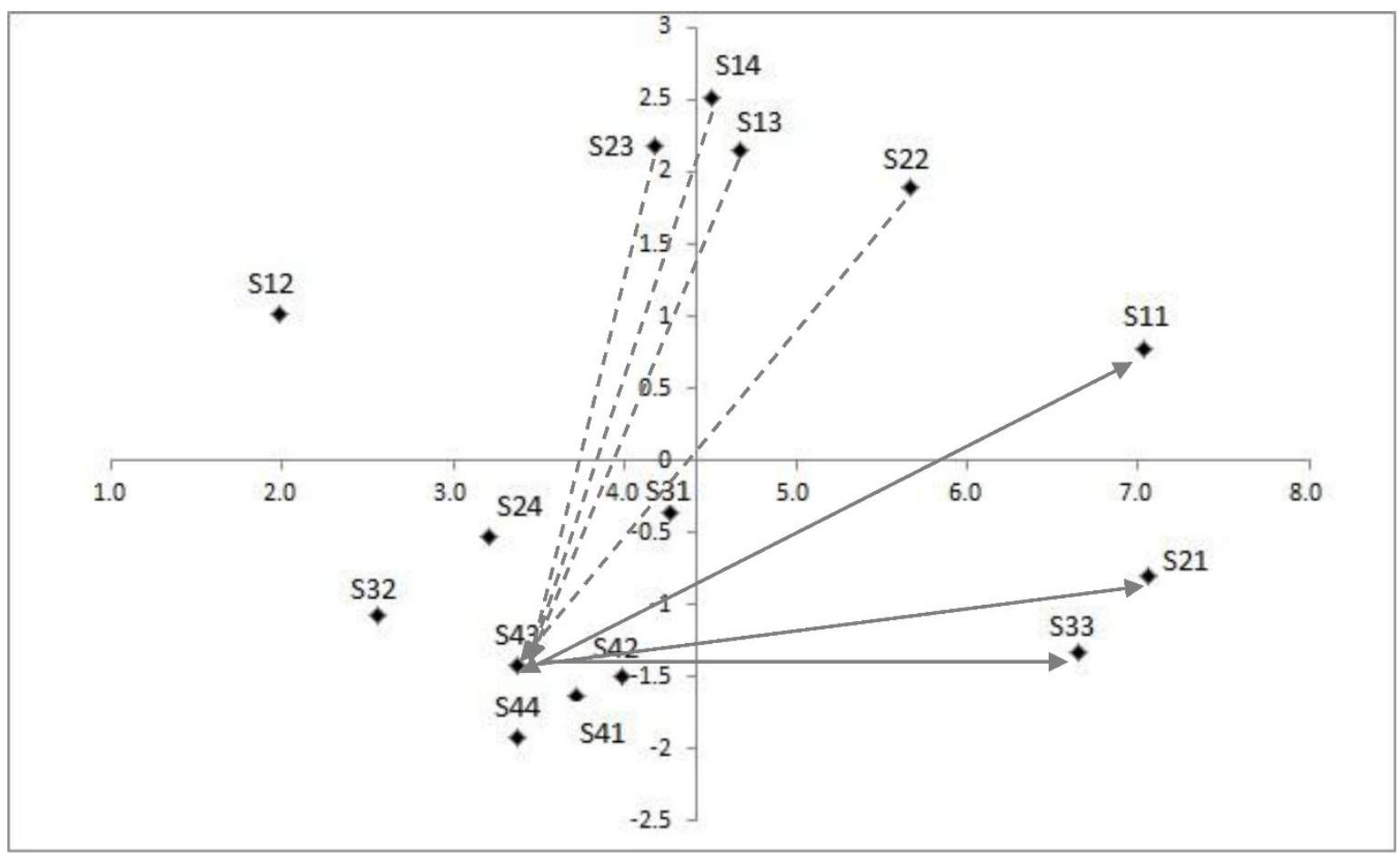

Figure A14. Casual Diagram between S43 and Other Criteria. 


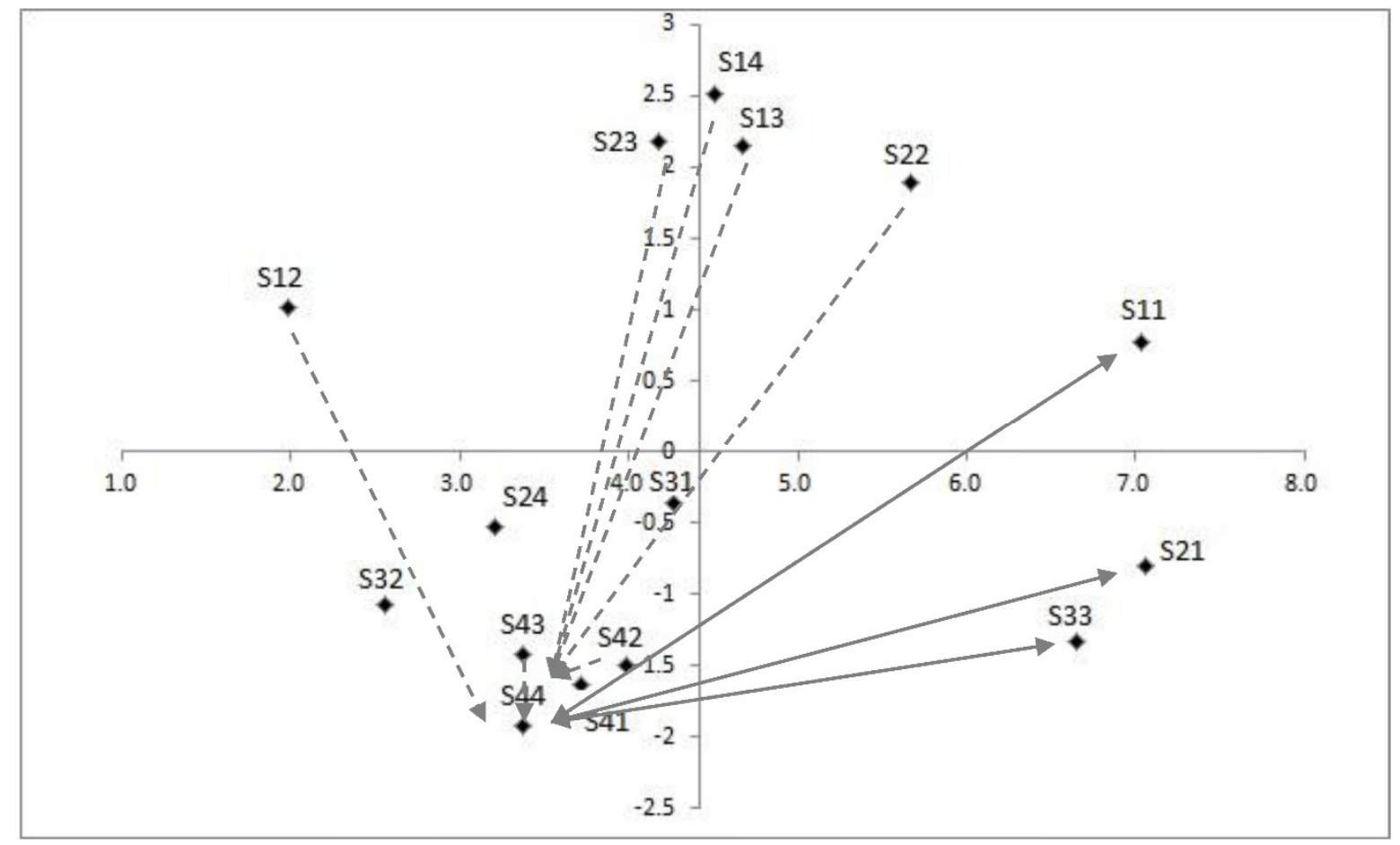

Figure A15. Casual Diagram between S44 and Other Criteria.

\section{References}

1. Drucker, P.F. Post-Capitalist Society; Butter Worth Heineman: New York, NY, USA, 1993.

2. Dougherty, D. A practice-centered model of organizational renewal through product innovation. Strateg. Manag. J. 1992, 13, 77-92.

3. Mohammad, Z.M. Using principles of just-in-time to improve new product development process. Adv. Compet. Res. 2003, 11, 116-124.

4. Liu, P.L.; Chen, W.C.; Tsai, C.H. An empirical study on the correlation between knowledge management method and new product strategy on product performance in Taiwan's industries. Technovation 2005, 25, 637-644.

5. Hollinsand, B.; Stuart, P. Successful Product Design; Butler Worth: London, UK, 1990.

6. Hung, S.W.; Tsai, J.M.; Cheng, M.J.; Chen, P.C. Analysis of the development strategy of late-entrants in Taiwan and Korea's TFT-LCD industry. Technol. Soc. 2012, 34, 9-22.

7. Industrial Economics Knowledge (IEK). 2012 Top Three Global Taiwan Industries/Product_Large TFT LCD Panel; IEK: Hsinchu, Taiwan, 2013.

8. Industrial Economics Knowledge (IEK). 2013 Large Global TFT LCD Industry Analysis; IEK: Hsinchu, Taiwan, 2014.

9. Industry \& Technology Intelligence Services (ITIS). 2014 Large Global TFT LCD Industry Development Trend; ITIS: Hsinchu, Taiwan, 2014.

10. Gima, K.A. Differential Potency of Factors Affecting Innovation Performance in Manufacturing and Services Firms in Australia. J. Prod. Innov. Manag. 1996, 13, 35-52.

11. Lee, S.; Yoon, B.; Park, Y. An approach to discovering new technology opportunities: Keyword-based patent map approach. Technovation 2009, 29, 481-497. 
12. Cooper, R.G. New Product Strategies: What Distinguishes the Top Performers? J. Prod. Manag. 1986, 2, 151-164.

13. Cooper, R.G. The Strategy-Performance Link in Product Innovation. $R \&$ D Manag. 1986, 84, 247-259.

14. Firth, R.W.; Narayanan, V.K. New Product Strategies of Large, Dominant Product Manufacturing Firms: An Exploratory Analysis. J. Prod. Innov. Manag. 1996, 3, 334-347.

15. Marion, T.J.; Friarand, J.H.; Simpson, T.W. New Product Development Practices and Early-Stage Firms: Two in-Depth Case Studies. J. Prod. Innov. Manag. 2012, 29, 639-654.

16. Chen, W.C.; Wang, L.Y.; Lin, M.C. A Hybrid MCDM Model for New Product Development: Applied on the Taiwanese $\mathrm{LiFePO}_{4}$ Industry. Math. Probl. Eng. 2015, 2015, 1-15.

17. Ulrich, K.T.; Eppinger, S.D. Product Design and Development; McGraw-Hill: New York, NY, USA, 2012.

18. Gabus, A.; Fontela, E. Perceptions of the World Problematique: Communication Procedure, Communicating with Those Bearing Collective Responsibility (DEMATEL Report No. 1); Battelle Geneva Research Center: Geneva, Switzerland, 1973.

19. Chen, J.K.; Chen, I.S. Using a novel conjunctive MCDM approach based on DEMATEL, fuzzy ANP, and TOPSIS as an innovation support system for Taiwanese higher education. Expert Syst. Appl. 2010, 37, 1981-1990.

20. Büyüközkan, G.; Çifçi, G. A novel hybrid MCDM approach based on fuzzy DEMATEL, fuzzy ANP and fuzzy TOPSIS to evaluate green suppliers. Expert Syst. Appl. 2012, 39, 3000-3011.

21. Yehand, T.M.; Huang, Y.L. Factors in determining wind farm location: Integrating GQM, fuzzy DEMATEL, and ANP. Renew. Energy 2014, 66, 159-169.

22. Hornga, J.S.; Liu, C.H.; Chou, S.F.; Tsaid, C.Y. Creativity as a critical criterion for future restaurant space design: Developing a novel model with DEMATEL application. Int. J. Hosp. Manag. 2012, 33, 96-105.

23. Abdollahi, M.; Arvan, M.; Razmi, J. An integrated approach for supplier portfolio selection: Lean or agile? Expert Syst. Appl. 2015, 42, 679-690.

24. Saaty, T.L. A scaling method for priorities in hierarchical structure. J. Math. Psychol. 1977, 15, 234-281.

25. Ayağ, Z. An integrated approach to evaluating conceptual design alternatives in a new product development environment. Int. J. Prod. Res. 2005, 43, 687-713.

26. Chin, K.S.; Xu, D.I.; Yang, J.B.; Lam, J.P.K. Group-based ER-AHP system for product project screening. Expert Syst. Appl. 2008, 35, 1909-1929.

27. Lin, M.C.; Wang, C.C.; Chen, M.S.; Chang, C.A. Using AHP and TOPSIS approaches in customer-driven product design process. Comput. Ind. 2008, 59, 17-31.

28. Li, Y.L.; Tang, J.F.; Chin, K.S.; Jiang, Y.S.; Han, Y.; Pu, Y. Estimating the final priority ratings of engineering characteristics in mature-period product improvement by MDBA and AHP. Int. J. Prod. Econ. 2011, 131, 575-586.

29. Saaty, T.L. The Analytic Network Process: Decision Making with Dependence and Feedback; RWS Publication: Pittsburgh, PA, USA, 2001.

30. Meade, L.M.; Sarkis, J. Analyzing organizational project alternatives for agile manufacturing processes-An analytical network approach. Int. J. Prod. Res. 1999, 37, 241-261. 
31. Lee, H.; Lee, S.; Park, Y. Selection of technology acquisition mode using the analytic network process. Math. Comput. Model. 2009, 49, 1274-1282.

32. Jharkharia, S.; Shankar, R. Selection of logistics service provider: An analytic network process (ANP) approach. Omega 2007, 35, 274-289.

33. Zadeh, L.A. Fuzzy sets. Inf. Control 1965, 8, 338-353.

34. Kardaras, D.K.; Karakostas, B.; Mamakou, X.J. Content presentation personalization and media adaptation in tourism web sites using Fuzzy Delphi Method and Fuzzy Cognitive Maps. Expert Syst. Appl. 2013, 40, 2331-2342.

35. Ma, Z.; Shao, C.; Ma, S.; Ye, Z. Constructing road safety performance indicators using Fuzzy Delphi Method and Grey Delphi Method. Expert Syst. Appl. 2011, 38, 1509-1514.

36. Chang, P.L.; Hsu, C.W.; Chang, P.C. Fuzzy Delphi method for evaluating hydrogen production technologies. Int. J. Hydrog. Energy 2011, 36, 14172-14172.

37. Wang, Y.; Yeo, G.T.; Ng, A.K.Y. Choosing optimal bunkering ports for liner shipping companies: A hybrid Fuzzy-Delphi-TOPSIS approach. Transp. Policy 2014, 35, 358-265.

38. Kim, K.J.; Moskowitz, H.; Dhingra, A.; Evans, G. Fuzzy multicriteria models for quality function deployment. Eur. J. Oper. Res. 2000, 121, 504-518.

39. Yuen, K.K.F. A hybrid fuzzy quality function deployment framework using cognitive network process and aggregative grading clustering: An application to cloud software product development. Neurocomputing 2014, 142, 95-106.

40. Zandi, F.; Tavana, M. A fuzzy group quality function deployment model for e-CRM framework assessment in agile manufacturing. Comput. Ind. Eng. 2011, 61, 1-19.

41. Lee, A.H.I.; Chen, W.C.; Chang, C.J. A fuzzy AHP and BSC approach for evaluating performance of IT department in the manufacturing industry in Taiwan. Expert Syst. Appl. 2008, 34, 96-107.

42. Alinezad, A.; Seif, A.; Esfandiari, N. Supplier evaluation and selection with QFD and FAHP in a pharmaceutical company. Int. J. Adv. Manuf. Technol. 2013, 68, 355-364.

43. Velmurugan, T. Performance based analysis between k-Means and Fuzzy C-Means clustering algorithms for connection oriented telecommunication data. Appl. Comput. 2014, 19, 134-146.

44. Chamoli, S. Hybrid FAHP-FTOPSIS approach for performance evaluation of the $\mathrm{V}$ down perforated baffle roughened rectangular channel. Energies 2015, 84, 432-442.

45. Promentilla, M.A.B.; Furuichi, T.; Ishii, K.; Tanikawa, N. A fuzzy analytic network process for multi-criteria evaluation of contaminated site remedial countermeasures. J. Environ. Manag. 2008, 88, 479-495.

46. Selvkli, M.; Oztekin, A.; Uysal, O.; Torlak, G.; Turkyilmaz, A.; Delen, D. Development of a fuzzy ANP based SWOT analysis for the airline industry in Turkey. Expert Syst. Appl. 2012, 39, 14-24.

47. Chen, W.C.; Chang, H.P. The application of fuzzy ANP in the development of new product decision-making - A case study of the solar module industry. Adv. Mater. Res. 2012, 472-475, 1333-1338.

48. Rezaeiniya, N.; Ghadikolaei, A.S.; Tekmeh, J.M.; Rezaeiniya, H. Fuzzy ANP approach for new application: Greenhouse location selection; a case in Iran. J. Math. Comput. Sci. 2014, 8, 1-20.

49. Chang, B.; Kuo, C.; Wu, C.H.; Tzeng, G.H. Using fuzzy analytic network process to assess the risks in enterprise resource planning system implementation. Appl. Comput. 2015, 28, 196-207.

50. Saaty, T.L. The Analytic Hierarchy Process; McGraw-Hill: New York, NY, USA, 1980. 
51. Saaty, T.L. How to make a decision: The analytic hierarchy process. Interfaces 1994, 24, $19-43$.

52. Buckley, J.J. Fuzzy hierarchical analysis. Fuzzy Sets Syst. 1985, 7, 233-247.

53. Chen, C.T. Extensions of TOPSIS for group decision-making under fuzzy environment. Fuzzy Sets Syst. 2000, 114, 1-9.

(C) 2015 by the authors; licensee MDPI, Basel, Switzerland. This article is an open access article distributed under the terms and conditions of the Creative Commons Attribution license (http://creativecommons.org/licenses/by/4.0/). 